\title{
DINUCLEAR COMPLEXES AS BUILDING BLOCKS FOR TETRA-NUCLEAR MACROCYCLIC COMPLEXES WITH DITHIOLATE MACROCYCLIC LIGAND
}

\author{
Vasile Lozan \\ Institute of Chemistry ASM, Academiei str., 3, Chisinau, MD 2028, R. Moldova \\ e-mail: vasilelozan@gmail.com
}

\begin{abstract}
A series of novel tri-, tetra- and pentanuclear complexes composed of dinuclear $\mathrm{LM}_{2}$ units $(\mathrm{M}=\mathrm{Co}, \mathrm{Ni}$, $\mathrm{Zn}$; L=24-membered macrocyclic hexaaza-dithiophenolate ligand) and ferrocene-carboxylate $\left(\left[\mathrm{CpFeC}_{5} \mathrm{H}_{4} \mathrm{CO}_{2}\right]^{-}\right)$, $1,1^{\prime}$-ferro-cenedicarboxylate $\left(\left[\mathrm{Fe}\left(\mathrm{C}_{5} \mathrm{H}_{4}-\mathrm{CO}_{2}\right)_{2}\right]^{2}\right)$, acetylenedicarboxylate, terephthalate, isophthalate, and naphthalene diimide dicar-boxylate groups is reported. The complexes have been synthesized and characterised by UV/Vis-, IR-spectroscopy, and X-ray crystallography. Each dicarboxylate dianion acts as a quadridentate bridging ligand linking two bioctahedral $\mathrm{LM}_{2}$ units via $\mu_{1,3}$-bridging carboxylate functions to generate discrete dications with a central $\mathrm{LM}_{2}\left(\mathrm{O}_{2} \mathrm{C}-\mathrm{R}-\mathrm{CO}_{2}\right) \mathrm{M}_{2} \mathrm{~L}$ core.
\end{abstract}

Keywords: coordination chemistry, amino-thiophenolate ligands, di- and tetranuclear complexes, ferrocene and naphthalene diimide derivatives, polynuclear complexes

\section{Introduction}

The chemistry of container molecules has developed extensively over the past two decades. Many container molecules such as calixarenes, resorcarenes, cyclodextrins, carcerands and glycourils have been invaluable in studying the fundamental principles of inclusion phenomena and consequently their use in separation science or drug delivery, as two examples of application. Importantly, the area has attracted interest in the field of supramolecular chemistry because the properties of such host-guest compounds are often different from those of their constituent components. By adjusting the size and form of the binding cavity it is often possible to complex co-ligands in unusual coordination modes, to activate and transform small molecules, or to stabilize reactive intermediates $[1,2]$. One subclass are the metallated container molecules, in which metal ions and clusters are used as both a point of recognition and to give the container a well-defined structure. Such compounds also allow for an interplay of molecular recognition and transition-metal catalysis, and for the construction of more effective enzyme mimics. Of interest to the present work is the ability of metallocavitands to recognize and encapsulate difunctionalised molecules towards stabilising or enhancing the optical and electronic properties of redox- and photo-active compounds within a confined environment set up by two hemispheres.

The carboxylate group, $\mathrm{RCO}^{2-}$, can bind to transition metals in a variety of coordination modes giving rise to complexes of great structural diversity [3]. Current activities focus on the coordination chemistry of polycarboxylate ligands, as these offer great potential in the construction of polynuclear aggregates [4] and extended coordination polymers with micro- and mesoporous structures [5-8] or catalytic properties [9]. In addition, polycarboxylate ligands are of importance as spin-coupling bridging ligands [10-17] in the rapidly expanding field of molecular magnetism $[18,19]$. In this context, an enormous amount of literature has been generated concerning the distance dependence of magnetic exchange interactions between metal atoms linked by extended dicarboxylate ligands. Dinuclear copper complexes bridged by oxalate [20,21] and terephthalate [22-24] dianions form, by far, the largest group of such systems, and it appears that the exchange interactions depend on the $\mathrm{M} \cdots \mathrm{M}$ distance [25], the relative orientation of the magnetic orbitals [26], and the degree of conjugation of the organic spacer unit [27, 28].
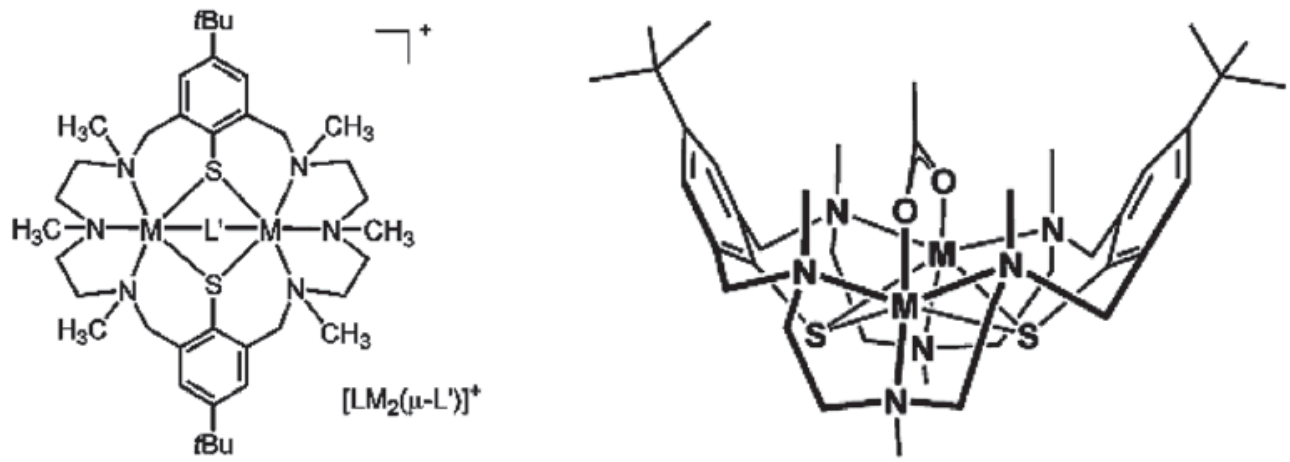

$$
\left[\mathrm{LM}_{2}^{\mathrm{II}}\left(\mathrm{L}^{\prime}\right)\right]^{+}\left(\mathrm{M}=\mathrm{Mn}^{\mathrm{II}}, \mathrm{Fe}^{\mathrm{II}}, \mathrm{Co}^{\mathrm{II}}, \mathrm{Ni}^{\mathrm{II}}\right)
$$

1. $\left[\left(\mathrm{LNi}_{2}{ }_{2}(\mu-\mathrm{Cl})\right]^{+}\right.$2. $\left[\left(\mathrm{LCo}_{2}{ }_{2}(\mu-\mathrm{Cl})\right]^{+}\right.$3. $\left[\left(\mathrm{LZn}_{2}{ }_{2}(\mu-\mathrm{OAc})\right]^{+}\right.$4. $\left[\left(\mathrm{LCo}_{2}{ }_{2}(\mu-\mathrm{OAc})\right]^{+}\right.$5. $\left[\left(\mathrm{LNi}_{2}{ }_{2}(\mu-\mathrm{OAc})\right]^{+}\right.$

Scheme 1. Dinuclear acetate-bridged complexes of the hexaaza-dithiophenolate ligand $\mathrm{L}^{2-}$ and their label. 
Recently, we reported the structures and magnetic properties of an isostructural series of bioctahedral $\left[\mathrm{LM}_{2}^{\mathrm{II}}(\mathrm{OAc})\right]^{+}$complexes, where $\mathrm{L}^{2-}$ represents a macrodinucleating $\mathrm{N}_{6} \mathrm{~S}_{2}$ supporting ligand (Scheme 1) [29]. Intramolecular antiferromagnetic exchange interactions are present in the $\mathrm{Mn}_{2}{ }_{2}{ }_{2} \mathrm{Fe}_{2}{ }_{2}$ and $\mathrm{Co}_{2}{ }_{2}$ complexes of this series with $J$ values of $-5.1,-10.6$, and $-2.0 \mathrm{~cm}^{-1}\left(\mathrm{H}=-2 J \mathrm{~S}_{1} \mathrm{~S}_{2}\right)$. In contrast, in the corresponding $\mathrm{Ni}_{2}{ }_{2}{ }^{2}$ complex a ferromagnetic exchange interaction is present with $J=+6.4 \mathrm{~cm}^{-1}$.

\section{Dicarboxylate dianions as a tetradentate bridged ligands.}

In view of the increasing interest in the targeted assembly of molecular-based magnetic materials using high-spin molecules of higher nuclearity [30-36], we considered it worthwhile to examine the possibility of linking pairs of dinuclear $\left[\mathrm{LNi}_{2}{ }_{2}\right.$ ] units by dicarboxylate dianions to form tetranuclear species. In the present contribution we report the synthesis and crystallographic characterization of three tetranuclear nickel (II) complexes of the type $\left[\mathrm{LNi}^{\mathrm{II}}{ }_{2}\right.$ dicarboxylateNi $\left.{ }_{2}^{\mathrm{II}} \mathrm{L}\right]$, where "dicarboxylate" stands for acetylenedicarboxylate, terephthalate, or isophthalate dianions. A schematic representation of these complexes is shown in Scheme 2. These complexes differ by the distance between the centre of the $\mathrm{Ni} \cdots \mathrm{Ni}$ axis of the isostructural $\mathrm{LNi}_{2}$ subunits, their relative orientation, and the nature of the bridging ligands. The ability of the dicarboxylate dianions to mediate magnetic exchange interactions between the dinuclear subunits is examined and discussed in the light of their specific structural features.

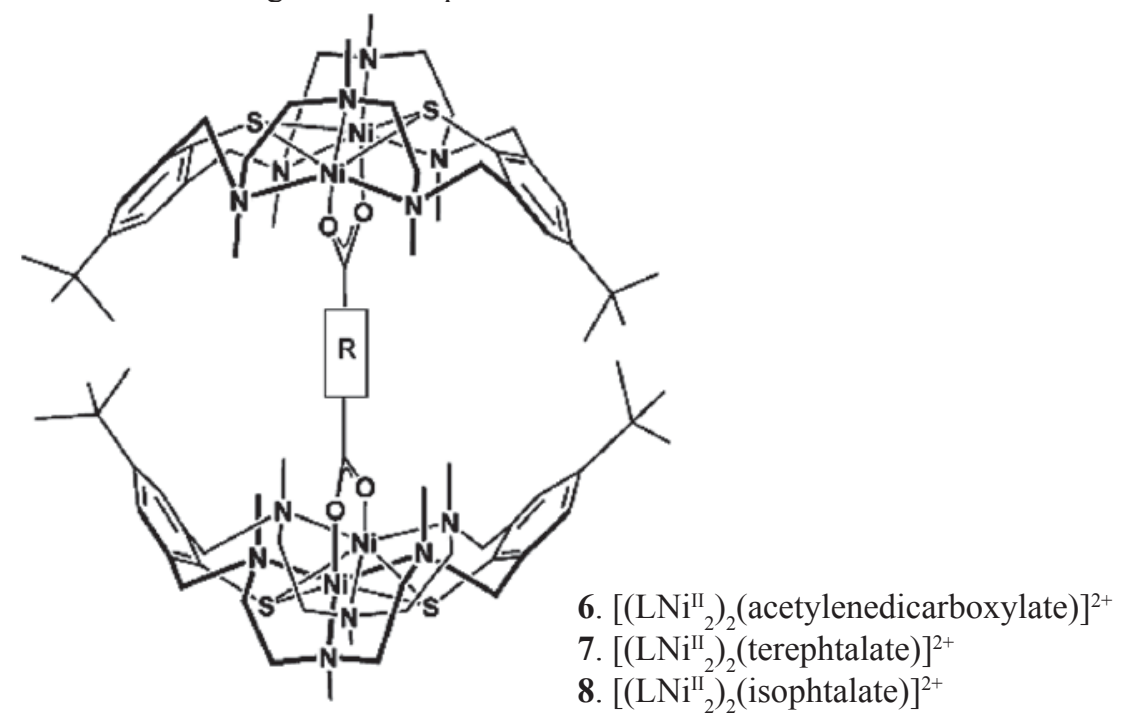

Scheme 2. Complexes prepared and their labels.

The complexes $\left[\left(\mathrm{LNi}_{2}{ }_{2}\right)_{2}\right.$ (acetylenedicarboxylato $\left.)\right]^{2+}(6),\left[\left(\mathrm{LNi}_{2}\right)_{2}(\text { terephthalato })\right]^{2+}(7)$, and $\left[\left(\mathrm{LNi}_{2}\right)_{2}\right)_{2}$ (isophthalato $)]^{2+}(\mathbf{8})$ were readily prepared from the reaction of the dinuclear complex $\left[\mathrm{LNi}^{\mathrm{II}}(\mu-\mathrm{Cl})\right]^{+}(\mathbf{1})$ and the corresponding triethylammonium dicarboxylate, prepared in situ from the acid and triethylamine in methanol in a 1:2 molar ratio, and isolated in high yield as the perchlorate or tetraphenylborate salts. The transformations are not simple substitution reactions, because simultaneous conformational changes of the supporting ligand $\mathrm{L}^{2-}$ from the folded $\left(\mathrm{C}_{\mathrm{s}}-\mathrm{symmetric}\right)$ to the "bowl-shaped" ( $\mathrm{C}_{\mathrm{\gamma}_{\mathrm{v}}}$-symmetric) conformation take place (see Scheme 3) [37].
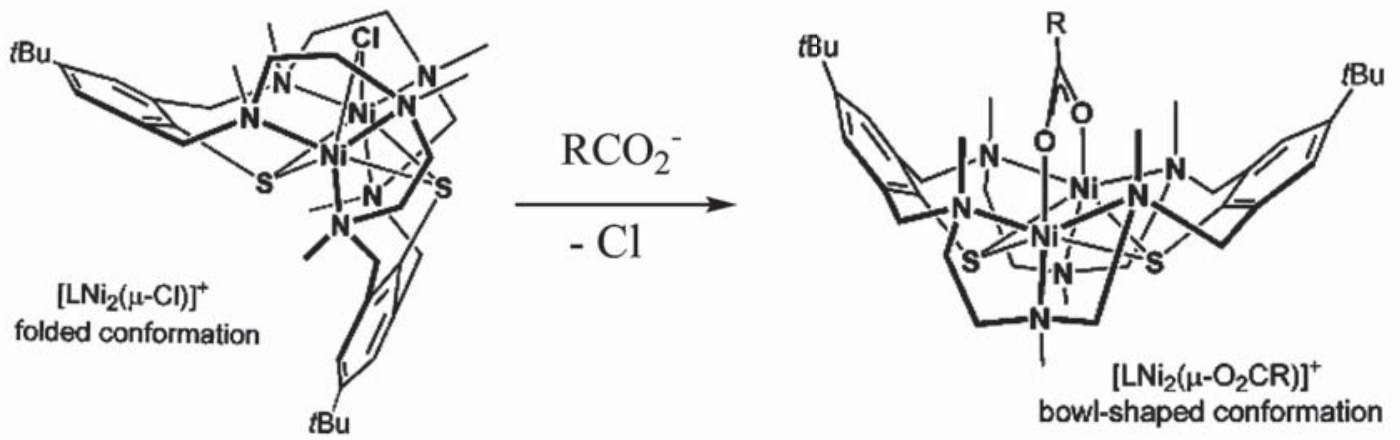

Scheme 3. Schematic representation of the two ligand conformations in the chloro- and carboxylato-bridged complexes of $(\mathrm{L})^{2-}$. For these conformational changes metal-ligand dissociations are required.

Nonetheless, linking of two $\left[\mathrm{LNi}_{2}\right]^{2+}$ fragments by the carboxylato ligands is a clean and facile step driven by the low solubility of the products. 
All compounds gave satisfactory elemental analyses and their IR spectra are marked by the prominent asymmetric and symmetric carboxylate stretching frequencies around $1580 \mathrm{~cm}^{-1}$ and $1420 \mathrm{~cm}^{-1}$, diagnostic of $\mu_{1,3}$-bridging carboxylate functions [38]. The UV/Vis spectra of 6-8 in acetonitrile display two weak bands above 500 nm typical of octahedral $\mathrm{Ni}^{2+}\left(\mathrm{d}^{8}, \mathrm{~S}=1\right)$ ions. The observed values compare closely with those of the acetato-bridged complex $\left[\mathrm{LNi}_{2}{ }_{2}(\mathrm{OAc})\right]^{+}$ [29], indicative of a pseudo-octahedral $\mathrm{N}_{3} \mathrm{~S}_{2} \mathrm{O}$ coordination environment about the metal ions. This is confirmed by single-crystal X-ray crystallography.

Crystals of $6\left[\mathrm{BPh}_{4}\right]_{2} \cdot 2 \mathrm{MeCN} \cdot 0.5 \mathrm{H}_{2} \mathrm{O}$ were obtained by slow evaporation of an acetonitrile/ethanol (1:1) solution of $6\left[\mathrm{BPh}_{4}\right]_{2}$. The crystal structure is composed of tetranuclear $\left[\left(\mathrm{LNi}_{2}{ }_{2}\right)_{2}\right.$ (acetylenedicarboxylate $\left.)\right]^{2+}$ dications, tetraphenylborate anions and acetonitrile and water solvates. Perspective drawings of the structure of $\mathbf{6}$ are depicted in Figure 1.
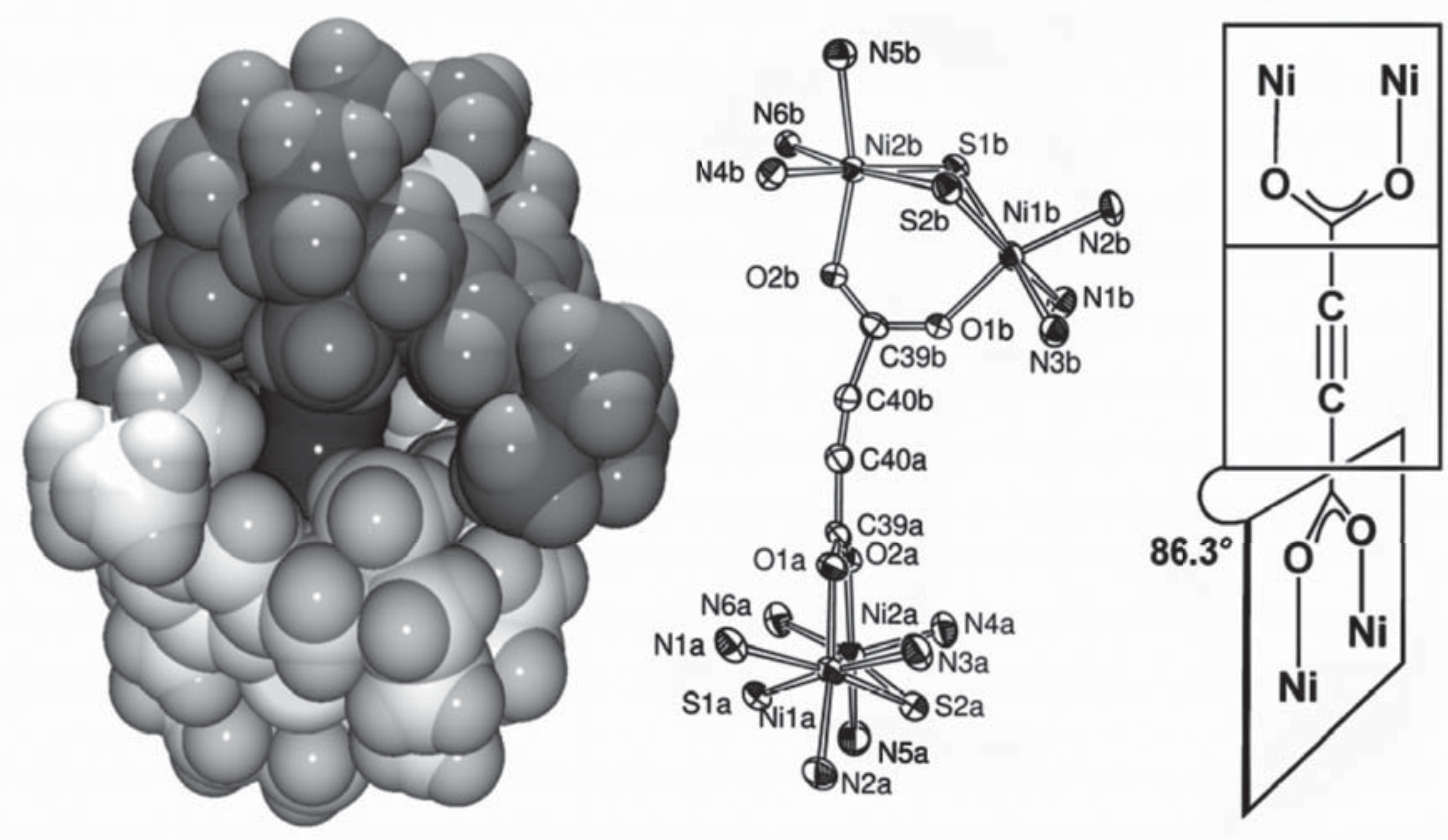

Figure 1. Left: Van der Waals plot of the $\left[\left(\mathrm{LNi}_{2}{ }_{2}\right)_{2}(\mu \text {-acetylenedicarboxylato })\right]^{2+}$ dication in crystals of $6\left[\mathrm{BPh}_{4}\right]_{2} \cdot 2 \mathrm{MeCN} \cdot 0.5 \mathrm{H}_{2} \mathrm{O}$. Middle: ORTEP representation of the core structure of 6 with the atom labeling scheme. Ellipsoids are represented at the $50 \%$ probability level. Right: Mutual orientation of the $\mathrm{Ni}_{2}$ carboxylato planes in 6.

The acetylenedicarboxylate dianion acts as a tetradentate bridging ligand joining two dinuclear $\left[\mathrm{LNi}_{2}\right]^{2+}$ fragments through its carboxylate functions to give a tetranuclear $\mathrm{Ni}_{2}-\left(\mathrm{O}_{2} \mathrm{CC} \equiv \mathrm{CCO}_{2}\right)-\mathrm{Ni}_{2}$ array. Each nickel atom is surrounded in a highly distorted octahedral fashion by two sulfur atoms and three nitrogen atoms from the supporting ligand, and one oxygen atom from the acetylenedicarboxylate moiety. The $\mathrm{Ni}_{2}$ carboxylato planes are necessarily twisted by $86.3^{\circ}$ about the $\mathrm{C} \equiv \mathrm{C}$ bond to relieve the unfavourable steric interactions between the bulky $t \mathrm{Bu}$ groups of the two opposing $\left[\mathrm{LNi}^{\mathrm{II}}{ }_{2}\right]^{2+}$ subunits. The coligand is also slightly bent $(\mathrm{C} \equiv \mathrm{C} 1.185(6) \AA$ Á) such that the intramolecular distances between two nickel atoms of different dinuclear subunits within the tetranuclear complex range from 8.623(1) to 9.769(1) $\AA$. The only system comparable to that of $\mathbf{6}$ is provided by the complex $\left[\left\{\mathrm{Mo}_{2}(\mathrm{DAniF})_{3}\right\}_{2}\left(\mathrm{O}_{2} \mathrm{CC} \equiv \mathrm{CCO}_{2}\right)\right]$, where $\mathrm{DAniF}=$ N,N'-di- $p$-anisylformamidinate, for which an intramolecular Mo $\cdots$ Mo distance of $9.537 \AA$ has been reported [39]. There are no significant intermolecular interactions between the $\mathrm{Ni}_{4}{ }_{4}$ complexes within the lattice. The shortest intermolecular $\mathrm{Ni} \cdots \mathrm{Ni}$ distance is at $7.470(1) \AA$.

Figure 2 shows the structure of the tetranuclear nickel(II) complex 7 in crystals of $7\left[\mathrm{BPh}_{4}\right]_{2} \cdot 2 \mathrm{EtOH} \cdot 0.5 \mathrm{MeCN} \cdot \mathrm{H}_{2} \mathrm{O}$. Again, the terephthalato ligand acts as a bifunctional linker coordinating to two bioctahedral $\left[\mathrm{LNi}_{2}\right]^{2+}$ entities via the carboxylate functions to generate a twisted $\mathrm{Ni}_{2}-\mathrm{O}_{2} \mathrm{C}-\mathrm{C}_{6} \mathrm{H}_{4}-\mathrm{CO}_{2}-\mathrm{Ni}_{2}$ motif. 

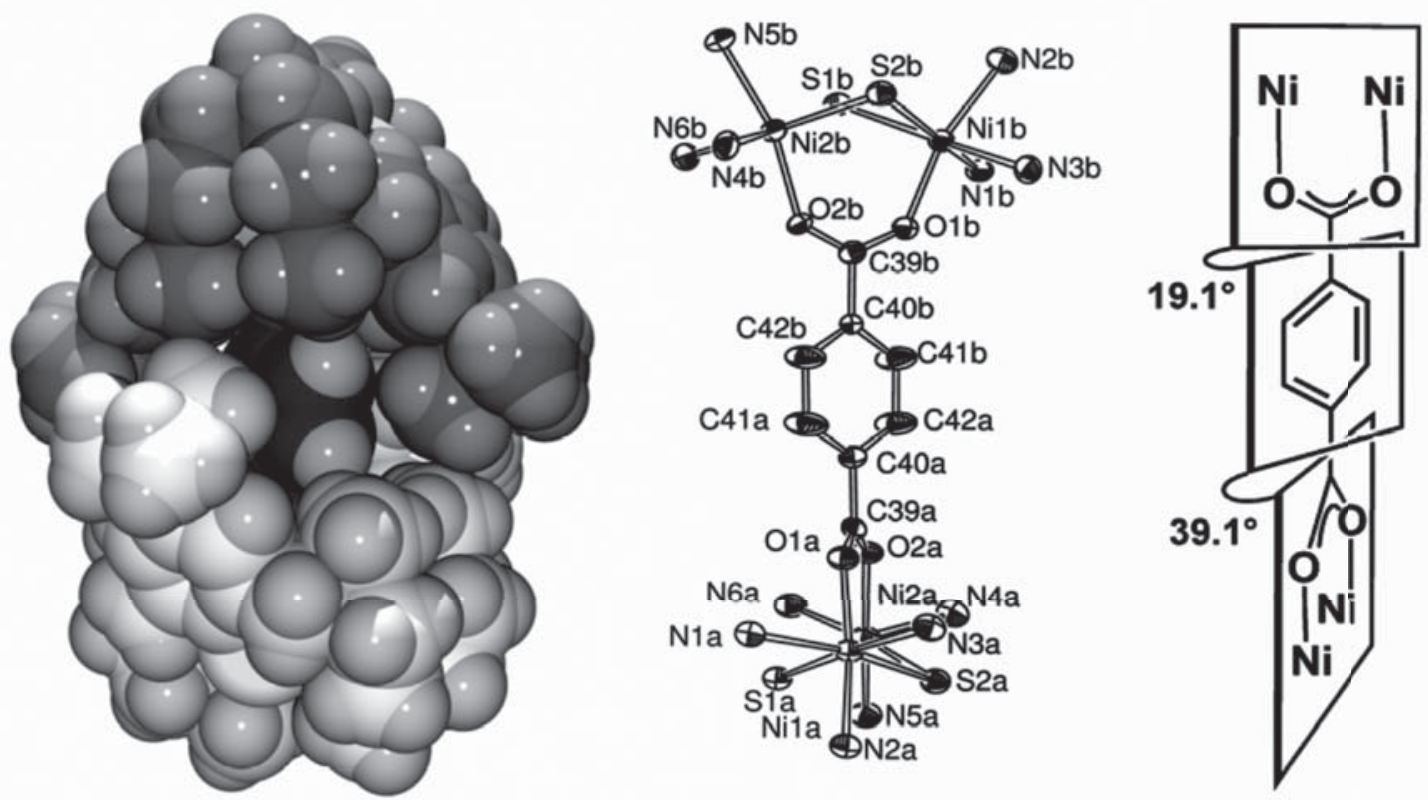

Figure 2. Left: Van der Waals representation of the $\left[\left(\mathrm{LNi}_{2}{ }_{2}\right)_{2}(\mu \text {-terephthalato })\right]^{2+}$ dication in crystals of $7\left[\mathrm{BPh}_{4}\right]_{2} \cdot 2 \mathrm{EtOH} \cdot 0.5 \mathrm{MeCN} \cdot \mathrm{H}_{2} \mathrm{O}$. Middle: ORTEP representation of the core structure of 7 with the atom labeling scheme. Ellipsoids are represented at the $50 \%$ probability level. Right: Relative orientation of the $\mathrm{Ni}_{2}$ carboxylato planes in 7 .

The $\left[\mathrm{LNi}_{2}\right]^{2+}$ subunits in $\mathbf{6}$ and $\mathbf{7}$ are structurally very similar, and the Ni-N, Ni-O, and Ni-S distances lie within very narrow ranges. As in $\mathbf{6}$, the $t \mathrm{Bu}$ groups of the two opposing $\mathrm{Ni}_{2}$ clusters are forced to interlock to accommodate the terephthalato ligand. This causes tilting of the carboxylato planes that are rotated by $58.2^{\circ}$ with respect to each other and by $19.1^{\circ}$ and $39.1^{\circ}$ with respect to the aromatic ring of the terephthalato coligand. Again, there are no intermolecular interactions between the tetranuclear complexes other than van der Waals contacts. The intramolecular $\mathrm{Ni} \cdots \mathrm{Ni}$ distances between the two dinuclear subunits are within the range 10.833(1)-11.155(1) $\AA$ (mean 10.990(1) $\AA$ ]. This is a typical value for terephthalato-bridged nickel(II) complexes [40,41].

Crystals of $\mathbf{8}\left[\mathrm{BPh}_{4}\right]_{2} \cdot 4 \mathrm{MeCN} \cdot \mathrm{EtOH}$ are triclinic, space group P1. ORTEP views of the structure of the dication $\mathbf{8}$ and the central core are provided in Figure 3.
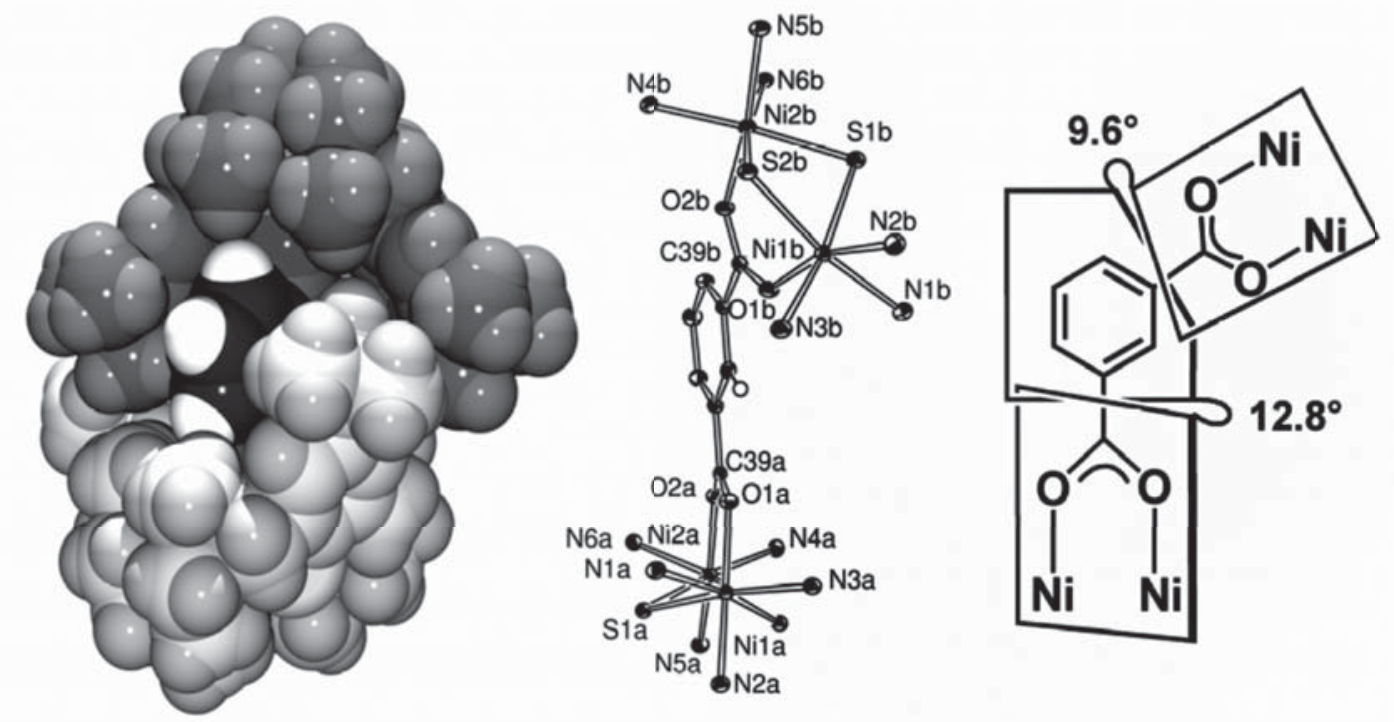

Figure 3. Left: ORTEP view of the $\left[\left(\mathrm{LNi}^{\mathrm{II}}\right)_{2}(\mu \text {-isophthalato })\right]^{2+}$ dication in crystals of $8\left[\mathrm{BPh}_{4}\right]_{2} \cdot 4 \mathrm{MeCN} \cdot \mathrm{EtOH}$.

Middle: ORTEP representation of the core structure of 8 with the atom labeling scheme. Ellipsoids are represented at the $50 \%$ probability level. Right: Tilting of the $\mathrm{Ni}_{2}$ carboxylato planes in 8 . 
The isophthalate dianion is bonded to two $\left[\mathrm{LNi}_{2}\right]^{2+}$ units through $\mu_{1,3}$-bridging carboxylate functions. The metalligand bond lengths within 8 reveal no anomalities and are very similar to those in $\mathbf{6}$ and $\mathbf{7}$. Strangely, the twisting of the carboxylato planes is less pronounced than in the previous cases. In fact, the two planes are almost coplanar with the phenyl ring of the bridging isophthalate dianion. The geometrical requirements of the isophthalate moiety with the two carboxylate functions in meta orientation leads to a distance of $9.561 \AA$ between the center of the $\mathrm{Ni} \cdots \mathrm{Ni}$ axes of the dinuclear units. This value should be compared with that of $10.712 \AA$ in 7 , where the two carboxylate functions are in para positions. The present coordination mode of the isophthalate dianion forming a discrete $\mathrm{Ni}_{4}{ }_{4}$ cluster is without precedence in the literature [42-44].

The magnetic properties of the three carboxylato-bridged complexes were examined in view of literature reports that conjugated dicarboxylate ligands are able to mediate long-range magnetic exchange interactions between paramagnetic metal ions [45]. The variable-temperature magnetic susceptibility data for $\mathbf{6}\left[\mathrm{BPh}_{4}\right]_{2}, 7\left[\mathrm{BPh}_{4}\right]_{2}$, and $^{8} \mathbf{8}[\mathrm{BPh}]_{2}$ were measured over the range 2.0-295 K using a SQUID magnetometer and an applied external magnetic field of $0.2 \mathrm{~T}$. Plots of the temperature dependence of the effective magnetic moment for $\mu_{\text {eff }}$ the three compounds are shown in Figure 4. The complexes have similar magnetic properties. At room temperature, the respective values of $\mu_{\text {eff }}$ are $6.91 \mu_{\mathrm{B}}, 6.82 \mu_{\mathrm{B}}$, and $7.13 \mu_{\mathrm{B}}$ per tetranuclear complex. With decreasing temperature the $\mu_{\mathrm{eff}}$ values increase steadily to maximum values of $7.85 \mu_{\mathrm{B}}(15 \mathrm{~K}), 7.71 \mu_{\mathrm{B}}(15 \mathrm{~K})$, and $8.03 \mu_{\mathrm{B}}(25 \mathrm{~K})$ for $\mathbf{6}\left[\mathrm{BPh}_{4}\right]_{2}, 7\left[\mathrm{BPh}_{4}\right]_{2}$, and $\mathbf{8}\left[\mathrm{BPh}_{4}\right]_{2}$, respectively. On lowering the temperature to $2.0 \mathrm{~K}$, these values decrease slightly down to $7.57 \mu_{\mathrm{B}}, 7.02 \mu_{\mathrm{B}}$, and $5.78 \mu_{\mathrm{B}}$ at $2 \mathrm{~K}$, presumably due to saturation effects or the zero-field splitting of nickel(II).

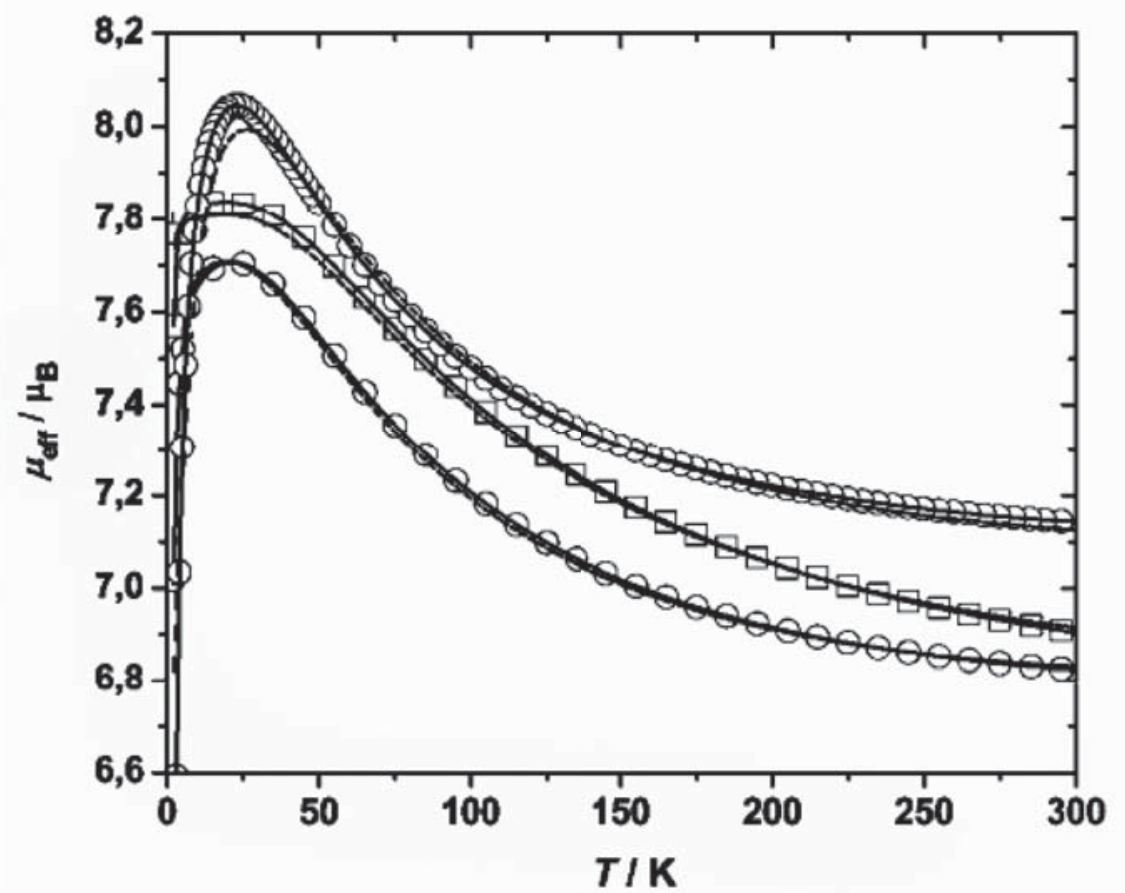

Figure 4. Temperature dependence of $\mu_{\text {eff }}$ (per tetranuclear complex) for $6\left[\mathrm{BPh}_{4}\right]_{2}$ (open squares), $7[\mathrm{BPh}]_{2}$ (open triangles), and $8\left[\mathrm{BPh}_{4}\right]_{2}$ (open circles). The full lines represent the best theoretical fits.

In all cases the maximum value of the effective magnetic moment is lower than expected for a spin-only value of $9.84 \mu_{\mathrm{B}}$ for $\mathrm{S}_{\mathrm{T}}=4$ resulting from ferromagnetic coupling of four $\mathrm{Ni}^{\mathrm{II}}\left(\mathrm{S}_{\mathrm{i}}=1, \mathrm{~g}=2.20\right)$ ions. However, the values are also significantly larger than the value of $6.22 \mu_{\mathrm{B}}$ calculated for completely uncoupled spins. The overall behaviour indicates the presence of weak ferromagnetic exchange interactions between the $\mathrm{Ni}^{2+}$ ions within the dinuclear subunits, but negligible, if any, coupling across the dicarboxylate bridges. The latter behaviour can be attributed to the long distance between the $\mathrm{Ni}^{2+}$ ions spanned by the dicarboxylates. In this regard, it is worthwhile noting that very weak exchange interactions have indeed been reported for other terephthalato- or isophthalato-bridged nickel(II) complexes $[28,46,47]$.

In summary, all three new compounds are discrete tetranuclear nickel(II) complexes composed of pairs of bioctahedral $\left[\mathrm{LNi}_{2}{ }_{2}\right]^{2+}$ units united by a tetradentate dicarboxylate anion. The calixarene-like conformation adopted by the supporting ligand leads to an almost complete encapsulation of the $\mathrm{Ni}_{2}\left(\mathrm{O}_{2} \mathrm{C}-\mathrm{R}-\mathrm{CO}_{2}\right) \mathrm{Ni}_{2}$ core. As a consequence the $\mathrm{Ni}_{4}{ }_{4}$ clusters are well-separated from each other in the solid state, featuring only intermolecular van der Waals contacts. 


\section{Redox-active ferrocenecarboxylates anions coordinated by dinuclear aminethiolate complexes}

Polynuclear complexes composed of classical and organometallic complex fragments have attracted considerable attention in recent years [48,49], owing to their rich redox chemistry [50, 51], the search for novel magnetic and electronic materials [52, 53], and potential applications in catalysis [51]. In addition, the presence of redox-active signalling groups and open coordination sites enables these compounds to be used as selective sensor molecules for target guest species [54-59]. So far, research in this area has mainly focused on conjugates built up of mononuclear LM complexes ( $\mathrm{L}=$ chelate ligand) and suitably functionalized ferrocene derivatives [60-63]. Less attention has been paid to the use of discrete dinuclear $\mathrm{LM}_{2}$ building blocks. The tetranuclear $\mathrm{Mo}_{4}$ complexes containing two quadruply bonded $\mathrm{Mo}_{2}$-formamidinate units linked by 1,1'-ferrocenedicarboxylate dianions may serve as rather rare examples of this class of compounds [64].

Recently, we described a series of dinuclear transition metal complexes supported by the macrocyclic hexaazadithiophenolate ligand $\mathrm{L}^{2-}$ (Scheme 4 ). These complexes have a rich coordination chemistry since the $\left[\mathrm{LM}_{2}\right]^{2+}$ fragments are able to coordinate a large variety of coligands such as $\mathrm{Cl}^{-}$[65], $\mathrm{OH}^{-}$[66], $\mathrm{NO}_{2}^{-}, \mathrm{NO}_{3}^{-}, \mathrm{N}_{3}^{-}$[67], $\mathrm{BH}_{4}^{-}$[68], and various carboxylates [69-71]. The extensive redox chemistry exhibited by dinuclear aminethiolate complexes [29] and the possibility of coupling these units into polynuclear arrays, led us to synthesize derivatives bearing ferrocenemonoand ferrocenedicarboxylate anions $\left(\left[\mathrm{CpFeC}_{5} \mathrm{H}_{4} \mathrm{CO}_{2}\right]^{-}\right.$and $\left[\mathrm{Fe}-\left(\mathrm{C}_{5} \mathrm{H}_{4} \mathrm{CO}_{2}\right)_{2}\right]^{2-}, \mathrm{Cp}=$ cyclopentadienyl $)$ as coligands. Our first attempts afforded a series of trinuclear $\left[\mathrm{LM}_{2}\left(\mathrm{O}_{2} \mathrm{CC}_{5} \mathrm{H}_{4} \mathrm{FeCp}\right)\right]^{+}$and pentanuclear $\left[\left(\mathrm{LM}_{2}\right)_{2}-\left(\mathrm{O}_{2} \mathrm{CC}_{5} \mathrm{H}_{4}\right)_{2} \mathrm{Fe}\right]^{2+}$ complexes. To our knowledge, these complexes represent the first class of compounds containing dinuclear aminethiolate complexes and redox-active ferrocenecarboxylates in the same molecule [72-75].

It was our aim to synthesize polynuclear complexes containing classical and organometallic complex fragments. Two types of complexes were considered: trinuclear $\left.\left[\mathrm{LM}_{2}{ }_{2}{ }_{2} \mathrm{O}_{2} \mathrm{CC}_{5} \mathrm{H}_{4} \mathrm{FeCp}\right)\right]^{+}$complexes and pentaneclear $\left[\left(\mathrm{LM}_{2}{ }_{2}\right)_{2}\left(\mathrm{O}_{2} \mathrm{CC}_{5} \mathrm{H}_{4}\right)_{2} \mathrm{Fe}\right]^{2+}$ compounds (here after abbreviated as $\mathrm{M}_{2}^{\mathrm{II}} \mathrm{Fe}$ and $\mathrm{M}_{4}^{\mathrm{II}} \mathrm{Fe}$ ), respectively. Scheme 4 shows the complexes prepared and their labels.
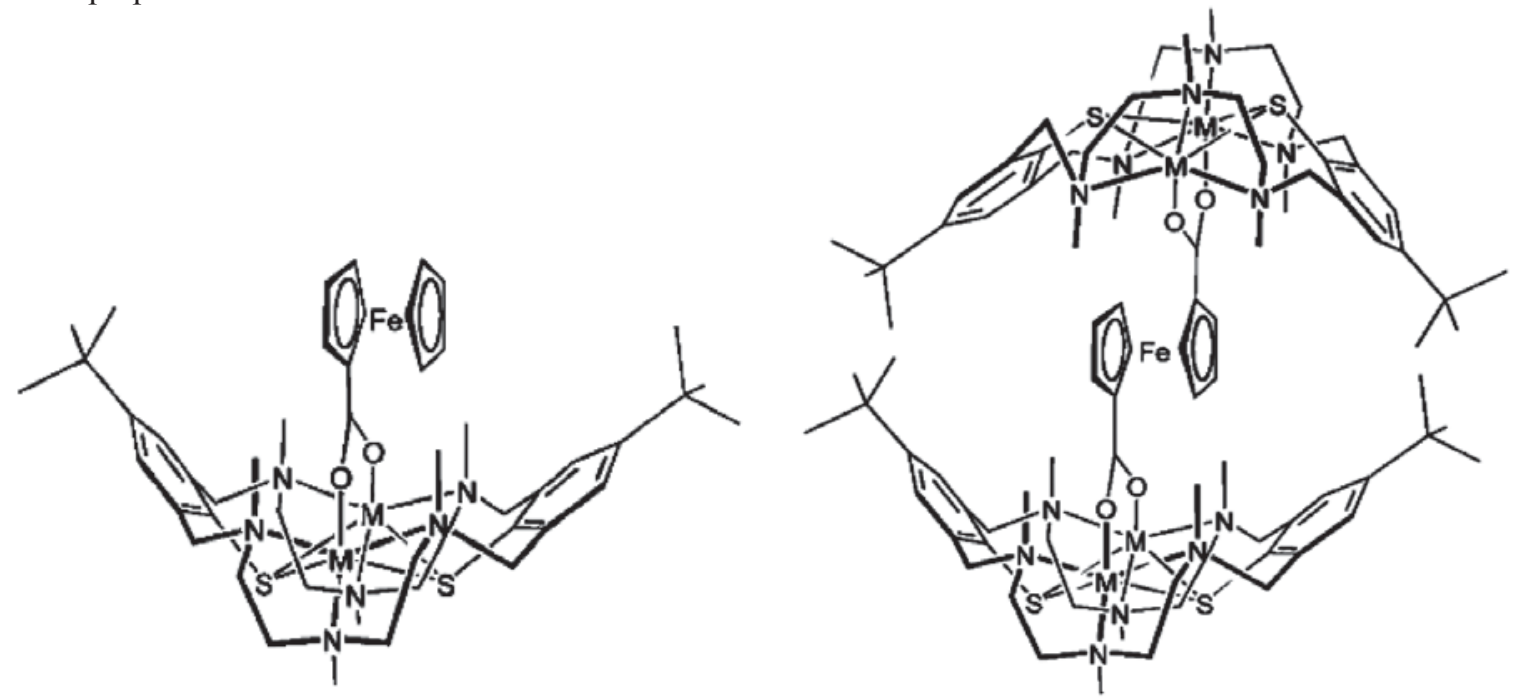

9. $\left[\mathrm{LCo}_{2}^{\mathrm{II}}\left(\mathrm{O}_{2} \mathrm{CC}_{5} \mathrm{H}_{4} \mathrm{FeCp}\right)\right]^{+} \mathbf{1 0} \cdot\left[\mathrm{LNi}_{2}{ }_{2}\left(\mathrm{O}_{2} \mathrm{CC}_{5} \mathrm{H}_{4} \mathrm{FeCp}\right)\right]^{+} \mathbf{1 1} \cdot\left[\mathrm{LZn}_{2}^{\mathrm{II}}\left(\mathrm{O}_{2} \mathrm{CC}_{5} \mathrm{H}_{4} \mathrm{FeCp}\right)\right]^{+}$
12. $\left.\left[\left(\mathrm{LCO}_{2}\right)_{2}\left(\mathrm{O}_{2} \mathrm{CC}_{5} \mathrm{H}_{4}\right)_{2} \mathrm{Fe}\right)\right]^{2+}$ 13. $\left.\left.\left[\left(\mathrm{LNi}_{2}\right)_{2}\left(\mathrm{O}_{2} \mathrm{CC}_{5} \mathrm{H}_{4}\right)_{2} \mathrm{Fe}\right)\right]^{2+} \mathbf{1 4} \cdot\left[\left(\mathrm{LCO}^{\mathrm{II}} \mathrm{Co}^{\mathrm{III}}\right)_{2}\left(\mathrm{O}_{2} \mathrm{CC}_{5} \mathrm{H}_{4}\right)_{2} \mathrm{Fe}\right)\right]^{4+}$

Scheme 4. Complexes prepared and their labels.

The trinuclear $\mathrm{Co}_{2} \mathrm{Fe}$ and $\mathrm{Ni}_{2} \mathrm{Fe}$ complexes, 9 and $\mathbf{1 0}$, were obtained in almost quantitative yield by reaction of the corresponding chloride complex $\left[\mathrm{LM}_{2}(\mu-\mathrm{Cl})\right]^{+}(\mathrm{M}=\mathrm{Ni}$ 1, Co 2) with triethylammonium ferrocenylmono-carboxylate (prepared in situ from $\mathrm{CpFeC}_{5} \mathrm{H}_{4} \mathrm{CO}_{2} \mathrm{H}$ and triethylamine) in a 1:3 ratio in methanol at room temperature and isolated as perchlorate salts upon addition of $\mathrm{LiClO}_{4}$. It should be noted that these reactions are not simple substitution reactions, because a simultaneous conformational change of the supporting ligand from a "partial-cone" to a "bowl-shaped" conformation takes place [76]. Since a chloro-bridged dizinc complex $\left[\mathrm{LZn}_{2}^{\mathrm{II}}(\mu-\mathrm{Cl})\right]\left[\mathrm{ClO}_{4}\right]$ is not yet known, the synthesis of the $\mathrm{Zn}_{2} \mathrm{Fe}$ complex $\mathbf{1 1}\left[\mathrm{ClO}_{4}\right]$ required another starting material. Complex $\left[\mathrm{LZn}_{2}{ }_{2}(\mu-\mathrm{OAc})\right]\left[\mathrm{ClO}_{4}\right]\left(\mathbf{3}\left[\mathrm{ClO}_{4}\right]\right)$ was chosen due to its proven ability to readily exchange its acetato group for more hydrophobic carboxylate anions [71]. Indeed, when $3\left[\mathrm{ClO}_{4}\right]$ is treated with a 10 -fold excess of triethylammonium ferrocenecarboxylate in methanol at room temperature an exchange reaction takes place and $\mathbf{1 1}\left[\mathrm{ClO}_{4}\right]$ can be isolated as an analytically pure yellow powder after workup. The three perchlorate salts $\mathbf{9}\left[\mathrm{ClO}_{4}\right]-\mathbf{1 1}\left[\mathrm{ClO}_{4}\right]$ are air-stable solids that are readily soluble in polar aprotic organic solvents such as dimethylformamide, dichloromethane, acetone and acetonitrile but only slightly soluble in methanol or ethanol. The corresponding tetraphenylborate salts $\mathbf{9}\left[\mathrm{BPh}_{4}\right]-\mathbf{1 1}\left[\mathrm{BPh}_{4}\right]$ are formed within a few minutes upon addition of ethanol solutions of $\mathrm{NaBPh}_{4}$ to acetonitrile solutions of the $\mathrm{ClO}_{4}^{-}$salts. 
The pentanuclear $\mathrm{Ni}_{4}{ }_{4}^{\mathrm{II}} \mathrm{Fe}$ and $\mathrm{Co}_{4}{ }_{4}^{\mathrm{II}} \mathrm{Fe}$ complexes $\left[\left(\mathrm{LM}_{2}\right)\left(\mu-\mathrm{O}_{2} \mathrm{CC}_{5} \mathrm{H}_{4}\right)_{2} \mathrm{Fe}\right]^{2+}(\mathrm{M}=\mathrm{Co}(\mathbf{1 2})$, Ni (13)) were prepared in much the same way as $\mathbf{9}$ and $\mathbf{1 0}$ : the chloride complexes $\mathbf{1}$ and $\mathbf{2}$ reacted smoothly with half an equivalent of triethylammonium 1,1'-ferrocenedicarboxylate (prepared in situ from the free acid and triethylamine) in methanol to give red-brown $\mathbf{1 2}\left[\mathrm{ClO}_{4}\right]_{2}$ and green $\mathbf{1 3}\left[\mathrm{ClO}_{4}\right]_{2}$, respectively, in nearly quantitative yields. The coupling of the dicarboxylate dianions with the $\left[\mathrm{LM}_{2}\right]^{2+}$ fragments is a clean and facile step driven forward by the low solubility of the products. The complexes are only slightly soluble in polar aprotic organic solvents such as DMF, dichloromethane, and acetonitrile and virtually insoluble in methanol or ethanol. Addition of $\mathrm{NaBPh}_{4}$ to suspensions of the perchlorate salts in acetonitrile/ ethanol followed by concentration in vacuum provided the corresponding tetraphenylborate salts as analytically pure products.

We have also been able to isolate the two-electron-oxidized $\mathrm{Co}^{\mathrm{II}} \mathrm{Co}^{\mathrm{III}}$ form $\mathbf{1 4}\left[\mathrm{ClO}_{4}\right]_{4}$ of compound $\mathbf{1 2}\left[\mathrm{ClO}_{4}\right]_{2}$. This mixed-valent complex was prepared as a black powder in good yields by oxidation of $\mathbf{1 2}\left[\mathrm{ClO}_{4}\right]_{2}$ with 1 equiv of bromine in acetonitrile at $0^{\circ} \mathrm{C}$ followed by addition of a saturated ethanol solution of $\mathrm{LiClO}_{4}$ and low-temperature vacuum concentration. In contrast to $12\left[\mathrm{ClO}_{4}\right]_{2}, \mathbf{1 4}\left[\mathrm{ClO}_{4}\right]_{4}$ exhibits excellent solubility in acetonitrile. Such solutions can be stored for several days at ambient temperature without noticeable decomposition. Attempts to prepare the analogous $\left[\left(\mathrm{LNi}^{\mathrm{II}} \mathrm{Ni}^{\mathrm{III}}\right)_{2}\left(\mu-\mathrm{O}_{2} \mathrm{CC}_{5} \mathrm{H}_{4}\right)_{2} \mathrm{Fe}\right]^{4+}$ complex were not successful.

All compounds gave satisfactory elemental analyses and were characterized by appropriate spectroscopic methods (IR, NMR, UV/Vis -spectroscopy). The infrared spectra of the new complexes display absorptions due to the $\left[\mathrm{LM}_{2}\right]^{2+}$ fragments, the counter ions $\left(\mathrm{ClO}_{4}^{-}\right.$or $\left.\mathrm{BPh}_{4}^{-}\right)$, and the ferrocene derivatives. The ferrocene-carboxylates in 9-13 give rise to two characteristic bands, as in other carboxylato-complexes [38, 77], in the $1575-1565 \mathrm{~cm}^{-1}$ and $1435-1425 \mathrm{~cm}^{-1}$ ranges; these are assigned to the asymmetric and symmetric carboxylate stretching modes, respectively. These values are very similar to those in 3-5 indicative of $\mu_{1,3}$-bridging carboxylate functions $[69,70]$. The oxidation of $\mathbf{1 2}$ to $\mathbf{1 4}$ is accompanied by a shift of the asymmetric stretching mode by $\approx 18 \mathrm{~cm}^{-1}$ to lower wavenumbers. A similar behaviour was observed for the acetato-bridged $\mathrm{Co}_{2}{ }_{2}$ complex 4 [70]. The data are thus in good agreement with the formulation of complex 14 as a mixed-valent $\mathrm{Co}^{\mathrm{II}} \mathrm{Co}^{\mathrm{III}}$ species.

The diamagnetic $\mathrm{Zn}_{2} \mathrm{Fe}$ complex 11 was characterized by NMR spectroscopy to determine its structure in solution. The ${ }^{~} \mathrm{H}$ NMR spectrum shows the characteristic signal patterns for the $\left[\mathrm{LZn}_{2}\right]^{2+}[78]$, and $\left[\mathrm{CpFe}\left(\mathrm{C}_{5} \mathrm{H}_{4} \mathrm{CO}_{2}\right)\right]^{-}[79]$, units indicating local $\mathrm{C}_{2 \mathrm{v}}$ symmetry for 11. Particularly indicative of a stable 1:1 complex is the upfield shift of the tert-butyl resonance of the [ $\left.\mathrm{LZn}_{2}\right]$ unit $(0.25 \mathrm{ppm}$ relative to 3$)$. The resonances of the ferrocenecarboxylate are observed at $\delta 3.40$ for the unsubstituted Cp ring, $\delta 3.90$ for the two meta-H and $\delta 4.04$ for the two ortho- $\mathrm{H}$ of the substituted $\mathrm{Cp}$ ring. These values are also significantly shifted to higher field when compared with the corresponding resonances of uncomplexed ferrocenmonocarboxylate $[80,81]$. The ${ }^{13} \mathrm{C}$ NMR spectrum is also in accord with the proposed formulation showing five signals for the $\left[\mathrm{CpFe}\left(\mathrm{C}_{5} \mathrm{H}_{4} \mathrm{CO}_{2}\right)\right]^{-}$unit and only 13 signals for the $\left[\mathrm{LZn}_{2}\right]^{2+}$ moiety. The local $\mathrm{C}_{2 \mathrm{v}}$ symmetry is suggestive of a dynamic averaging process in solution. A rapid rotation of the ferrocenyl group about the $\mathrm{CpFeCp}-\mathrm{CO}_{2} \mathrm{Zn}_{2} \mathrm{~L}$ bond seems most likely. This motion would result in the coalescence of the respective signals and the time averaged $\mathrm{C}_{2 \mathrm{v}}$ symmetry of the complex. The crystal structure determinations of $\mathbf{9}$ and $\mathbf{1 0}$ support this assumption.

The UV/Vis spectra of $\mathbf{9 , 1 0 , 1 2}$, and $\mathbf{1 3}$ display several weak bands above $500 \mathrm{~nm}$ typical of octahedral high-spin $\mathrm{Co}^{\mathrm{II}}\left(\mathrm{d}^{7}, \mathrm{~S}=3 / 2\right)$ and $\mathrm{Ni}^{\mathrm{II}}\left(\mathrm{d}^{8}, \mathrm{~S}=1\right)$ ions, respectively. The observed values closely compare with those of $\mathbf{4}$ and $\mathbf{5}$ again consistent with pseudo-octahedral $\mathrm{N}_{3} \mathrm{~S}_{2} \mathrm{O}$ coordination environments around the metal atoms $[69,70]$. For the $\mathrm{Zn}_{2} \mathrm{Fe}$ species $11\left[\mathrm{ClO}_{4}\right]$ two absorptions bands are detected at 342 and $440 \mathrm{~nm}$; these are readily assigned to the $\mathrm{d}-\mathrm{d}$ transitions of the coordinated $\left[\mathrm{CpFe}\left(\mathrm{C}_{5} \mathrm{H}_{4} \mathrm{CO}_{2}\right)\right]^{-}$unit. The feature at $440 \mathrm{~nm}$ is also evident in the electronic absorption spectrum of the $\mathrm{Ni}_{2} \mathrm{Fe}$ complex 10. In the UV spectrum of 11, this band is obscured by an intense ligand-to-metal charge-transfer transition $\left(\mathrm{RS} \rightarrow \mathrm{Co} 0^{I}\right)$. The $\mathrm{d}-\mathrm{d}$ transitions of the $\left[\mathrm{Fe}\left(\eta^{5}-\mathrm{C}_{5} \mathrm{H}_{4} \mathrm{CO}_{2}\right)\right]^{2-}$ unit in 12, $\mathbf{1 3}$ and $\mathbf{1 4}$ could not be located.

The UV/Vis spectrum of the mixed-valent $\mathrm{Co}^{\mathrm{II}} \mathrm{Co}^{\mathrm{III}}$ complex $\mathbf{1 4}$ is dominated by two very intense absorptions at $\approx 449$ and $681 \mathrm{~nm}$; these are attributable to $\mathrm{RS} \rightarrow \mathrm{Co}^{\mathrm{III}}$ charge-transfer transitions. Such intense LMCT transitions are characteristic of thiolato-bridged $\mathrm{Co}^{\mathrm{II}} \mathrm{Co}^{\mathrm{III}}$ complexes. The corresponding absorptions in $\left[\mathrm{LCo}^{\mathrm{II}} \mathrm{Co}^{\mathrm{III}}(\mu-\mathrm{OAc})\right]^{2+}$, for example, were observed at 460 and $710 \mathrm{~nm}$ [70]. It should be noted that the UV/Vis spectrum of 14 reveals no bands attributable to intervalence transfer (IT) bands. Complex 14 is therefore presumably class I in Robin and DayOs classification of mixed-valence species with distinct localized high-spin $\mathrm{Co}^{\mathrm{II}}$ and low-spin $\mathrm{Co}^{\mathrm{III}}$ sites [82]. This is confirmed by the crystal structure determination of $\mathbf{1 4}\left[\mathrm{ClO}_{4}\right]_{4}$.

Crystals of $9\left[\mathrm{BPh}_{4}\right] \cdot 3 \mathrm{MeCN}$ suitable for X-ray crystallography were grown by slow evaporation of a dilute 1:1 acetonitrile/ethanol solution of $9\left[\mathrm{BPh}_{4}\right]$. The X-ray structure revealed the presence of well-separated $\left[\mathrm{LCo}_{2}{ }_{2}(\mu-\right.$ $\left.\left.\mathrm{O}_{2} \mathrm{CC}_{5} \mathrm{H}_{4} \mathrm{FeCp}\right)\right]^{+}$cations, tetraphenylborate anions, and acetonitrile molecules of solvent of crystallization. An ORTEP representation of the molecular structure of 9 is shown in Figure 5. 


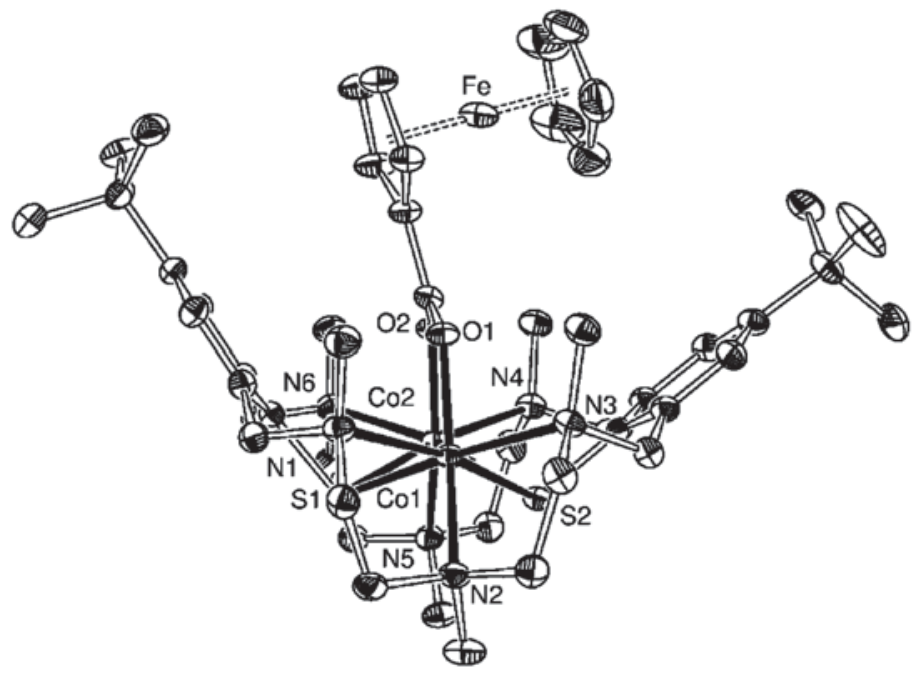

Figure 5. Structure of the cation 9 in crystals of $9\left[\mathrm{BPh}_{4}\right] \cdot 3 \mathrm{MeCN}$. Thermal ellipsoids are drawn at the $30 \%$ probability level. Hydrogen atoms are omitted for reasons of clarity. Only one orientation of a rotationally disordered $t \mathrm{Bu}$ group is shown.

The ferrocenecarboxylate bridges the two Co atoms in a $\mu_{1,3}$-fashion, resulting in nonbonded Co $\cdots$ Fe separations of 5.884(1) and 5.753(1) $\AA$. The Co $\cdots$ Co distance of 3.448(1) $\AA$ is the same as that in 4 [67]. The Cp rings are nearly parallel (angle between the normals of the $\mathrm{Cp}$ planes $=1.8(1)^{\circ}$ ) and adopt an almost eclipsed conformation, with the torsional angle $\tau$ (defined as " $\mathrm{CO}_{2}$-centroid-centroid-C(45)") being $6.4(1)^{\circ}$. The carboxylato plane is slightly twisted by $9.7^{\circ}$ with respect to the $\mathrm{Cp}$ ring to which it is attached. The Fe-centroid distances are 1.656(6) and 1.646(6) $\AA$ for the carboxylated and the unsubstituted $\mathrm{Cp}$ rings, respectively; the mean Fe-ring (centroid) distance of 1.651(6) $\AA$ is, within experimental error, the same as that of 1.645(2) $\AA$ for ferrocene [83]. The bond lengths and angles around the Co atoms within the $\left[\mathrm{LCO}_{2}{ }_{2}\right]^{2+}$ unit reveal no unusual features. The average $\mathrm{Co}-\mathrm{S}, \mathrm{Co}-\mathrm{N}$ and $\mathrm{Co}-\mathrm{O}$ bond lengths are at 2.018(3), 2.291(3), and 2.517(1) $\AA$, respectively. Virtually the same distances are seen in the acetato-bridged complex 4 [67]. A large number of metal complexes containing ferrocenecarboxylate ligands have been structurally characterized [84-86]; to our knowledge, 9 is the first such complex supported by a dinuclear aminethiolate metallo ligand.

In contrast to the compound above, $\mathbf{1 0}\left[\mathrm{BPh}_{4}\right]$ recrystallized from acetonitrile/ethanol 1:1 with only one acetonitrile solvate molecule. Figure 6 shows the ferrocenecarboxylate to be coordinated to the $\left[\mathrm{LNi}^{\mathrm{II}}{ }_{2}\right]$ unit in a manner identical to the situation found in 9 (Figure 5).

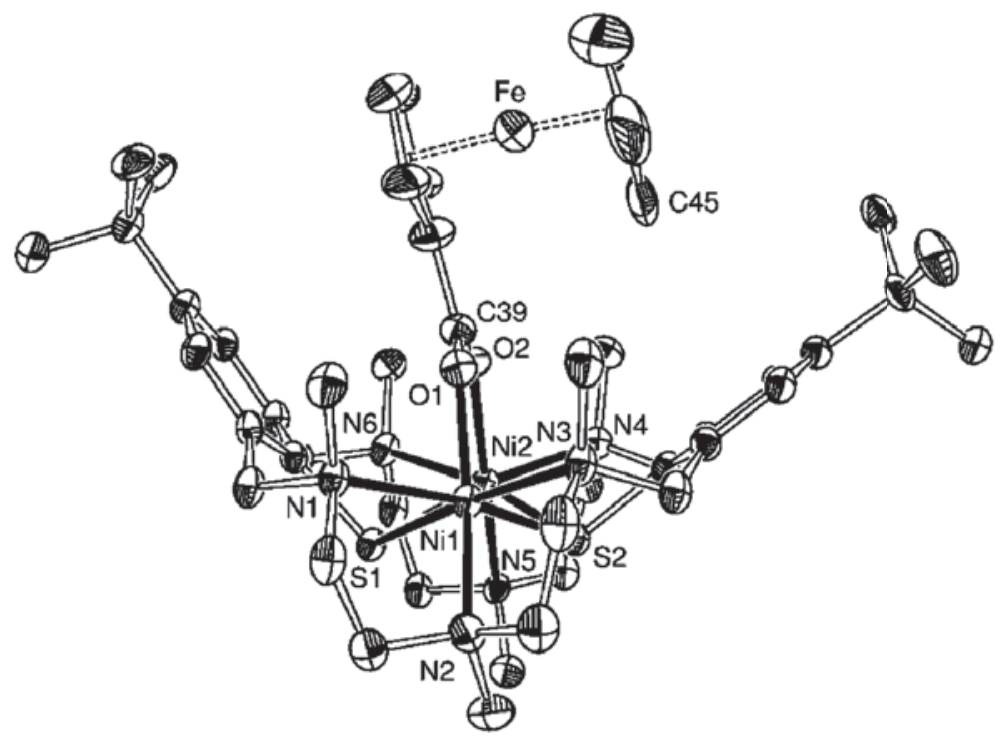

Figure 6. Structure of the cation 10 in crystals of $10\left[\mathrm{BPh}_{4}\right] \cdot \mathrm{MeCN}$. Thermal ellipsoids are drawn at the $30 \%$ probability level. Hydrogen atoms are omitted for reasons of clarity. Only one orientation of a rotationally disordered $t \mathrm{Bu}$ group is shown. 
Thus, both $\mathrm{Ni}^{\mathrm{iI}}$ ions are six coordinate with three $\mathrm{N}$ and two $\mathrm{S}$ atoms from $\mathrm{L}^{2-}$ and one $\mathrm{O}$ atom of a $\mu_{1,3}$-bridging ferrocenyl carboxylate group. In comparison to 9 , the two $\mathrm{Cp}$ rings are perfectly eclipsed (tilt angle $=0.6(1)^{\circ}$ ) and the carboxylato plane is now coplanar with the Cp ring $(\tau=2.88)$. The different $\boldsymbol{\tau}$ values may be taken as evidence for an unhindered rotation of the coordinated ferrocene moiety about the $\mathrm{O}_{2} \mathrm{C}-\mathrm{Cp}$ bond in the solution state. It should be noted in this respect that there are no intramolecular steric interactions between the ferrocene group and the $t \mathrm{Bu}$ substituents. The short distances between $\mathrm{C}(45)$ and the $\boldsymbol{p}$-electrons of the adjacent phenyl ring $(\boldsymbol{d}(\mathrm{C} 45) \cdots$ centroid $=3.518 \AA$ in $\mathbf{1 0}$ and $3.991 \AA$ in 9) may be considered as weak $\mathrm{CH}^{\cdots} \cdots \boldsymbol{\pi}$ hydrogen bonds. The $\mathrm{Ni}-\mathrm{O}, \mathrm{Ni}-\mathrm{N}$, and $\mathrm{Ni}-\mathrm{S}$ distances of the [ $\mathrm{LNi}_{2}$ carboxylate] subunit in $\mathbf{1 0}$ are unexceptional and are very close to the corresponding distances in $\mathbf{5}$. Overall, the two structures clearly show that the $\left[\mathrm{LM}_{2}\right]^{2+}$ units can expand their binding pockets sufficiently to accommodate $\mu_{1,3}{ }^{-}$ bridging ferrocenecarboxylate ions.

Single crystals of the two compounds $12[\mathrm{BPh}]_{4} \cdot 2^{2} /{ }_{3} \mathrm{MeCN} \cdot 1 /{ }_{3} \mathrm{H}_{2} \mathrm{O}$ and $\left.13[\mathrm{BPh}]_{2}\right]_{2} \cdot 1.75 \mathrm{MeCN} \cdot \mathrm{EtOH} \cdot 0.25 \mathrm{H}_{2} \mathrm{O}$ suitable for X-ray crystallography were each obtained by slow evaporation from an acetonitrile/ethanol/ $\mathrm{CH}_{2} \mathrm{Cl}_{2}$ solution. The crystal structures consist of isolated $\left[\left(\mathrm{LM}_{2}\right)_{2}\left(\mathrm{O}_{2} \mathrm{CC}_{5} \mathrm{H}_{4}\right)_{2} \mathrm{Fe}\right]^{2+}$ dications (Figure 7), tetraphenylborate anions and various solvate molecules $\left(\mathrm{MeCN}, \mathrm{H}_{2} \mathrm{O}\right.$, and $\left.\mathrm{EtOH}\right)$, of which some are either severely disordered or not fully occupied.

a)

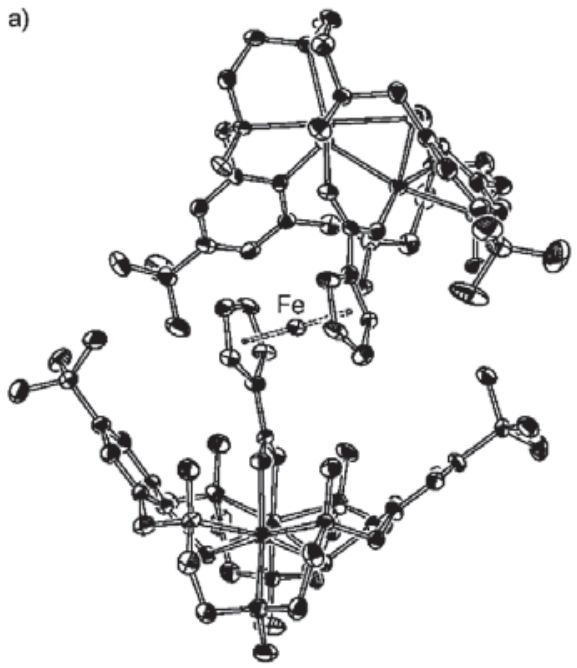

b)

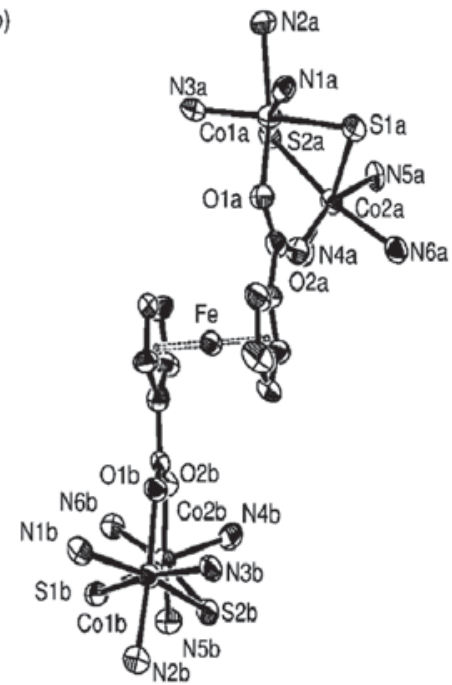

Figure 7. a) ORTEP view of the $\left[\left(\mathrm{LCo}_{2}^{\mathrm{II}}\right)_{2}\left(\mu-\mathrm{O}_{2} \mathrm{CC}_{5} \mathrm{H}_{4}\right)_{2} \mathrm{Fe}\right]^{2+}$ dication 12 in crystals of $12\left[\mathrm{BPh}_{4}\right]_{2} \cdot{ }^{2} /{ }_{3} \mathrm{MeCN}$ $.1 /{ }_{3} \mathrm{H}_{2} \mathrm{O}$. Hydrogen atoms are omitted for clarity. b) ORTEP representation of the core structure of 12 with the atom labelling scheme. Ellipsoids are represented at the $30 \%$ probability level.

The two compounds were found to be isomorphous in spite of differences in the number and type of solvate molecules. The following discussion will focus on the $\mathrm{Co}_{4}{ }^{\mathrm{II}} \mathrm{Fe}$ complex 12. Metrical details for the $\mathrm{Ni}_{4}{ }^{\mathrm{II}} \mathrm{Fe}$ complex $\mathbf{1 3}$ are reported in square brackets.

As can be seen in Figure $7 \mathrm{~b}$, the ferrocenyldicarboxylate dianion links two $\left[\mathrm{LCo}_{2}\right]^{\mathrm{II}}{ }^{2+}$ units via two $\mu_{1,3}$-bridging carboxylate functions. The $\left[\mathrm{LCo}_{2}\right]^{2+}$ subunits in $\mathbf{1 2}$ and $\mathbf{4}$ are structurally very similar, and the $\mathrm{Co}-\mathrm{N}, \mathrm{Co}-\mathrm{O}$, and $\mathrm{Co}-\mathrm{S}$ distances lie within very narrow ranges. The carboxylato groups on the $\mathrm{Cp}$ rings assume an anti-eclipsed conformation as manifested by a torsional angle $\boldsymbol{\tau}\left(\mathrm{CO}_{2}\right.$-centroid-centroid- $\left.\mathrm{CO}_{2}\right)$ of $148.4^{\circ}\left[148.3^{\circ}\right]$. The distance $\boldsymbol{d}$ between the centre of the $\mathrm{Co} \cdots \mathrm{Co}$ axes of the binuclear subunits amounts to $10.751 \AA[10.749 \AA]$, which is slightly smaller than the corresponding distance in $\left[\mathrm{Mo}_{2}(\mathrm{DAniF})_{3}\right]_{2}$ [ferrocendicarboxylate] [64]. It should be noted that the $\mathrm{Co}_{2}$ carboxylato planes are considerably tilted against each other $\left(32.3^{\circ},\left[33.1^{\circ}\right]\right)$ and also with respect to their corresponding $\mathrm{Cp}$ rings $\left(22.4^{\circ}, 10.1^{\circ} ;\left[22.4^{\circ}, 10.0^{\circ}\right]\right)$. This distortion from coplanarity relates to steric interactions between the $t$ Bu groups of the two opposing $\left[\mathrm{LCO}_{2}{ }_{2}\right]^{2+}$ subunits. The tert-butyl groups must interlock to accommodate the dicarboxylate ion. In ferrocenedicarboxylato complexes of sterically less encumbered supporting ligands the carboxylato planes are both coplanar with their parent $\mathrm{Cp}$ rings $[87,88]$.

The crystal structure of $\mathbf{1 4}\left[\mathrm{ClO}_{4}\right]_{4} \cdot 4 \mathrm{H}_{2} \mathrm{O}$ consists of $\left[\left(\mathrm{LCo}^{\mathrm{II}} \mathrm{Co}^{\mathrm{III}}\right)_{2}\left(\mu-\mathrm{O}_{2} \mathrm{CC}_{5} \mathrm{H}_{4}\right)_{2} \mathrm{Fe}\right]^{4+}$ cations (Figure 8), $\mathrm{ClO}_{4}^{-}$ anions and water solvate molecules. There are two crystallographically independent but chemically almost identical molecules (labelled A and B) in the asymmetric unit; both have crystallographically imposed $\mathrm{C}_{2}$ symmetry with the iron atoms residing on crystallographic two-fold axes. The overall structure of complex $\mathbf{1 4}$ is very similar to that of its parent 12, featuring two binuclear $\mathrm{LCo}_{2}$ subunits linked by a tetradentate ferrocenedicarboxylate ion. Again, the carboxylato 
groups are anti-eclipsed $\left(\boldsymbol{\tau}=148.6^{\circ}\left[136.9^{\circ}\right.\right.$ (molecule B)] and considerably tilted against each other $\left(48.2^{\circ},\left[25.2^{\circ}\right]\right)$ and by $24.1^{\circ}\left[12.6^{\circ}\right]$ with respect to their corresponding Cp rings. The distance $\boldsymbol{d}$ between the centre of the Co드 axes is $10.770 \AA$ in molecule A and $10.322 \AA$ in molecule B.
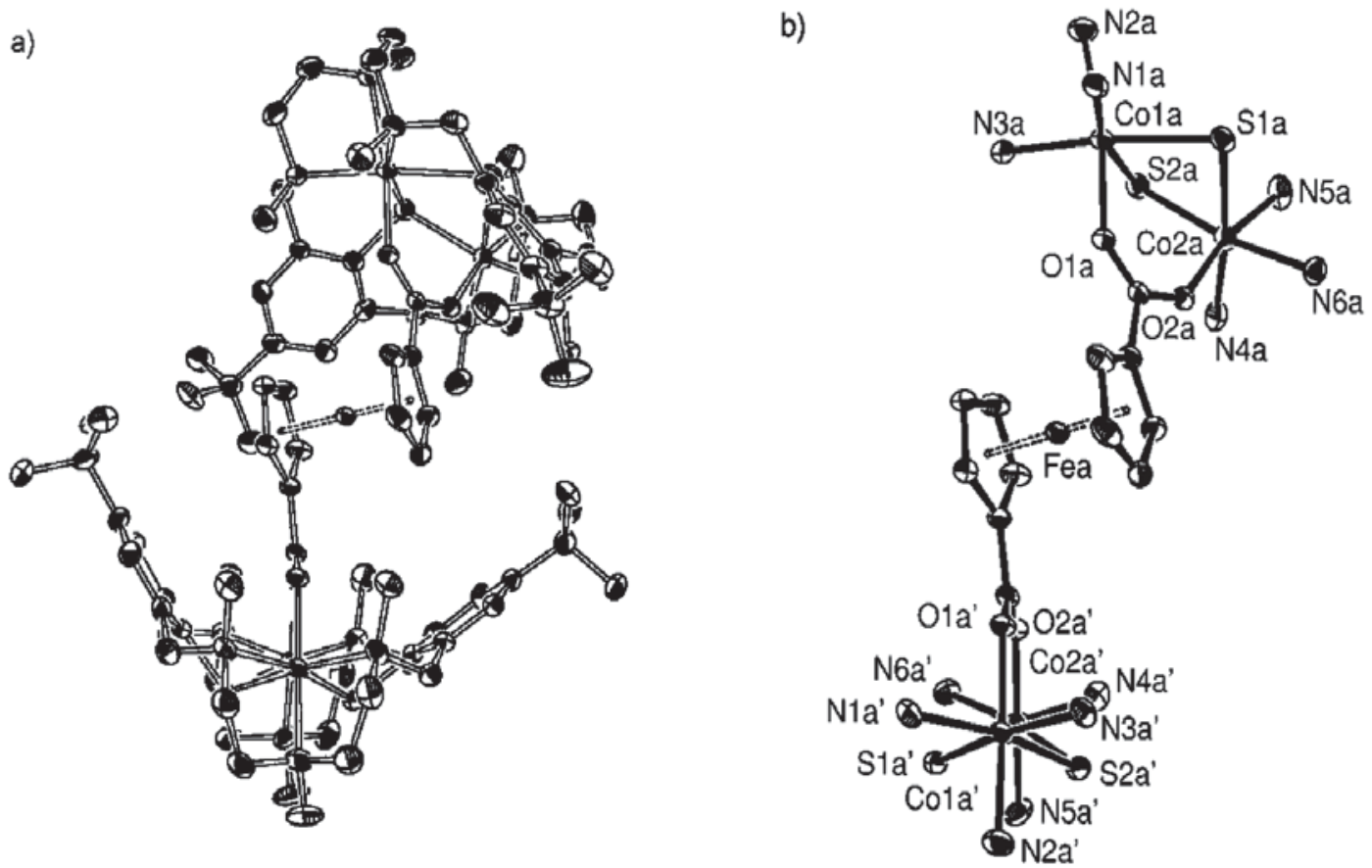

Figure 8. a) ORTEP view of the $\left[\left(\mathrm{LCo}^{\mathrm{III}} \mathrm{Co}^{\mathrm{II}}\right)_{2}\left(\mu-\mathrm{O}_{2} \mathrm{CC}_{5} \mathrm{H}_{4}\right)_{2} \mathrm{Fe}\right]^{4+}$ tetracation (molecule $\left.\mathrm{A}\right)$ in crystals of $14\left[\mathrm{ClO}_{4}\right]_{2} \cdot 4 \mathrm{H}_{2} \mathrm{O}$. Hydrogen atoms are omitted for clarity. b) ORTEP representation of the core structure of 14 with the atom labelling scheme. Ellipsoids are drawn at the $30 \%$ probability level.

The oxidation of $\mathbf{1 2}$ to $\mathbf{1 4}$ is accompanied by a significant shortening of the metal-ligand bond lengths around one Co atom in each binuclear subunit. This is in accord with the mixed-valent nature of $\mathbf{1 4}$ and the metal-centred nature of the oxidation of 12. Assignments of the trivalent and divalent Co ions are based on the bond distances around the cobalt atoms. Co1a [Colb in molecule B] is assigned an oxidation state $+\mathrm{II}\left(\mathrm{d}^{7}\right.$, high-spin), because the bond lengths are very similar to those in 12. The average $\mathrm{Co}-\mathrm{O}, \mathrm{Co}-\mathrm{N}$ and $\mathrm{Co}-\mathrm{S}$ bond lengths around $\mathrm{Co} 2 \mathrm{a}$ [Co2b] are all significantly shorter at 1.884(4), 2.122(6), and 2.311(2) $\AA$, respectively. These distances are too short for a six-coordinate $\mathrm{Co}^{\mathrm{II}}$ complex, but are in excellent accord with those of related low-spin $\mathrm{Co}^{I I I} \mathrm{~N}_{6-\mathrm{x}} \mathrm{S}_{x}[89,90]$ and $\mathrm{Co}^{\mathrm{III}} \mathrm{N}_{3} \mathrm{~S}_{2} \mathrm{O}$ [67] complexes. Interestingly, the oxidation of 12 is accompanied by an opening up of the Co-S-Co angle to $93.56(7)^{\circ}$ causing a slight increase of the intramolecular Co $\cdots$ Co distance to 3.523(1) $\AA$. The Fe-Cp-ring (centroid) distances (1.653(6) $\AA$ and 1.651(6) $\AA$ ) are not affected by the oxidation.

Evidently, the crystal structures of 12-14 clearly show that dinuclear $\mathrm{LM}_{2}$ units can be coupled together by the 1,1'-ferrocendicarboxylate dianion. Moreover, the pentanuclear $\mathrm{Co}_{4} \mathrm{Fe}$ complex 12 is even accessible in another oxidation state. The oxidation is metal-centered and occurs without gross structural changes of the parent complex 12. This finding paves the way for novel multi-redox systems composed of binuclear complex units and multifunctional metalorganic linkers which may find applications due to novel chemical or physico-chemical properties that are not seen for the individual components [91].

One facet of the present complexes is the presence of a redox-active ferrocene unit in close proximity to one or two redox-active $\left[\mathrm{LM}_{2}\right]^{2+}$ groups. This feature suggests that electron transfer events can influence one another owing to the short distance $(5.6 \pm 0.2 \AA)$ between the redox centres. To determine whether this is the case, cyclovoltammetric studies have been carried out on the $\mathrm{M}_{2}$ Fe complexes $\mathbf{9}\left[\mathrm{ClO}_{4}\right]-\mathbf{1 1}\left[\mathrm{ClO}_{4}\right]$ and the $\mathrm{Co}_{4} \mathrm{Fe}$ compound $\mathbf{1 4}\left[\mathrm{ClO}_{4}\right]_{4}$. The cyclic voltammograms (CV's) have been recorded in acetonitrile solution with tetra- $n$-butylammonium hexafluorophosphate as the supporting electrolyte. The electrochemical results are shown in Figure 9, and the redox potentials referenced versus SCE are collected in Table 1. 


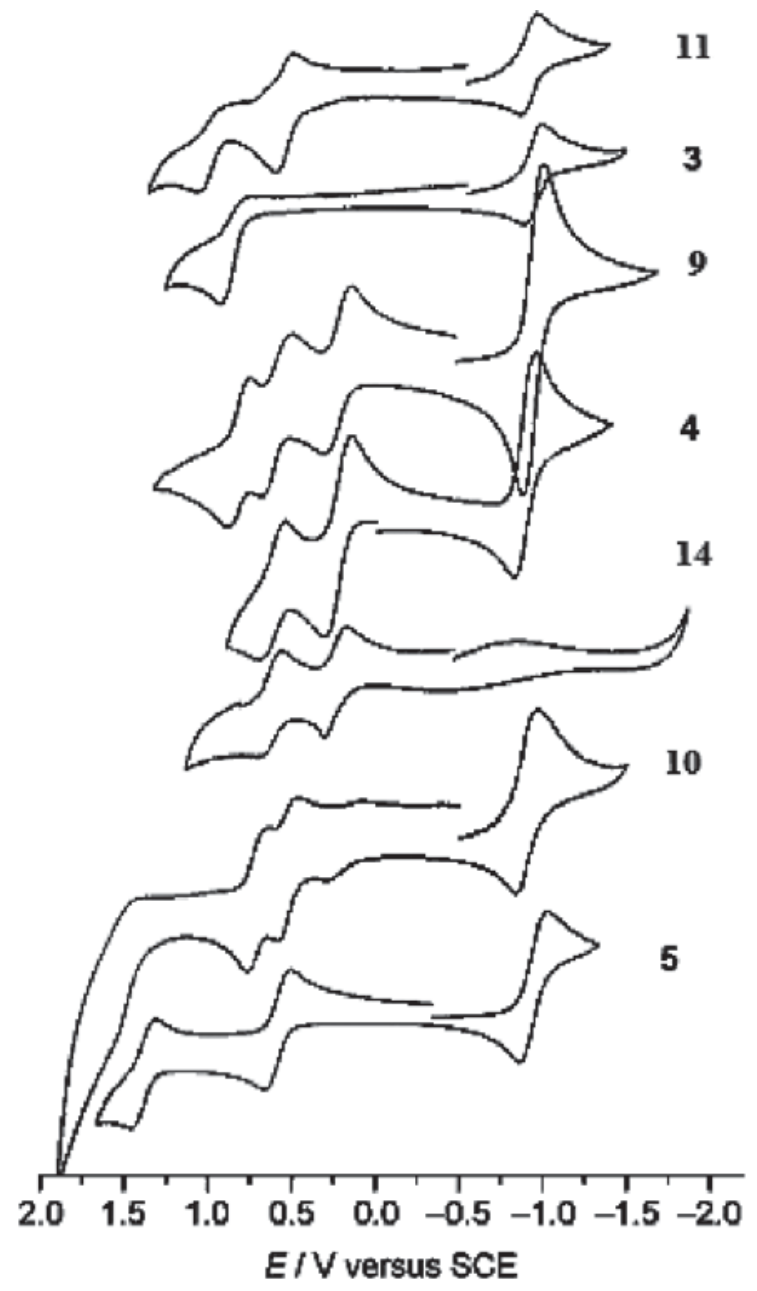

Figure 9. Cyclic voltammograms of the perchlorate salts of complexes 3-5, 9-11 and 14 in $\mathrm{CH}_{3} \mathrm{CN}_{\text {solution at }}$ 295K. Experimental conditions: $0.1 \mathrm{M}\left[{ }^{\mathrm{n}} \mathrm{Bu}_{4} \mathrm{~N}\right]\left[\mathrm{PF}_{6}\right]$ supporting electrolyte, ca. $1 \times 10^{-3} \mathrm{M}$ sample concentration, Pt disk working, Pt wire auxiliary electrodes, $\mathrm{Ag}$ wire reference electrode, scan rate $=100 \mathrm{mV} \mathrm{s}^{-1} \cdot\left[\mathrm{Co}\left(\mathrm{Cp}_{2}\right]\left[\mathrm{PF}{ }_{6}\right]\right.$ internal standard $\left(\mathrm{E}\left[\mathrm{CoCp}{ }_{2}{ }^{+} / \mathrm{CoCp}_{2}\right]=-0.94 \mathrm{~V}\right.$ versus $\left.\mathrm{SCE}\right)$.

Table 1

Electrochemical data, E[V] vs SCE, for the compounds examined in this study. ${ }^{[b]}$

\begin{tabular}{|c|c|c|c|c|}
\hline Compound & Solvent & $\mathrm{Fe}^{\mathrm{III}} / \mathrm{Fe}^{\mathrm{II}}$ & $\begin{array}{cc}\mathbf{E}_{1 / 2}[\mathbf{V}](\Delta \mathrm{Ep}[\mathrm{mV}])^{\mathrm{b}} \\
\mathbf{M}^{\mathrm{III}} \mathbf{M}^{\mathrm{II}} / \mathbf{M}^{\mathrm{II}}{ }_{2} \quad \mathbf{M}_{2}^{\mathrm{III}} / \mathbf{M}^{\mathrm{III}} \mathbf{M}^{\mathrm{II}}\end{array}$ & $\mathbf{R S}^{-} / \mathbf{R S}$ \\
\hline $3 \cdot\left[\mathrm{ClO}_{4}\right]^{[29]}$ & $\mathrm{CH}_{3} \mathrm{CN}$ & & & $0.92(\text { irr. })^{[\mathrm{d}]}$ \\
\hline $4 \cdot\left[\mathrm{ClO}_{4}\right]^{[29]}$ & $\mathrm{CH}_{3} \mathrm{CN}$ & & $0,60(147)$ & \\
\hline $5 \cdot\left[\mathrm{ClO}_{4}\right]^{[29]}$ & $\mathrm{CH}_{3} \mathrm{CN}$ & & $1,36(140)$ & \\
\hline $9 \cdot\left[\mathrm{ClO}_{4}\right]$ & $\mathrm{CH}_{3} \mathrm{CN}$ & $0,81(120)$ & $0,59(170)$ & \\
\hline $10 \cdot\left[\mathrm{ClO}_{4}\right]$ & $\mathrm{CH}_{3} \mathrm{CN}$ & $0,55(120)$ & 1,54 (irr.) ${ }^{[\mathrm{d}]}$ & \\
\hline $11 \cdot\left[\mathrm{ClO}_{4}\right]$ & $\mathrm{CH}_{3} \mathrm{CN}$ & $0,54(100)$ & & 1.06 (irr.) $)^{[\mathrm{d}]}$ \\
\hline $14 \cdot\left[\mathrm{ClO}_{4}\right]$ & $\begin{array}{l}\mathrm{CH}_{3} \mathrm{CN} \\
\mathrm{DMF}\end{array}$ & $\begin{array}{l}\text { Obsc. } \\
\text { Obsc. }\end{array}$ & $\begin{array}{l}0,23(140) \\
0,17(120)\end{array}$ & \\
\hline$\left[\mathrm{FeCp}_{2}\right]^{[55]}$ & $\mathrm{CH}_{3} \mathrm{CN}$ & 0,40 & & \\
\hline$\left[\mathrm{CpFe}\left(\mathrm{C}_{5} \mathrm{H}_{4} \mathrm{CO}_{2} \mathrm{H}\right)\right]^{[91]}$ & $\begin{array}{l}\text { aq. } \mathrm{CH}_{3} \mathrm{CN} \\
\mathrm{CH}_{3} \mathrm{CN}\end{array}$ & $\begin{array}{c}0,53 \\
0,63(50)\end{array}$ & & \\
\hline$\left[\mathrm{CpFe}\left(\mathrm{C}_{5} \mathrm{H}_{4} \mathrm{CO}_{2}\right)\right]^{-[\mathrm{cc}[91]}$ & $\begin{array}{l}\text { aq. } \mathrm{CH}_{3} \mathrm{CN} \\
\mathrm{CH}_{3} \mathrm{CN} \\
\end{array}$ & $\begin{array}{l}0,34 \\
0,44 \\
\end{array}$ & & \\
\hline$\left[\mathrm{CpFe}\left(\mathrm{C}_{5} \mathrm{H}_{4} \mathrm{CO}_{2} \mathrm{H}\right)_{2}\right]$ & DMF & $0,80(0.10)$ & & \\
\hline
\end{tabular}

${ }^{[a]}$ The CV's were recorded at ambient temperature using $0.10 \mathrm{M}\left[{ }^{\mathrm{n}} \mathrm{Bu}_{4} \mathrm{~N}\right]\left[\mathrm{PF}_{6}\right]$ as supporting electrolyte at a scan rate of $100 \mathrm{mV} \mathrm{s}^{-1}$. The data refer to the perchlorate salts. Sample concentration was ca. $1.0 \times 10^{-3} \mathrm{M}$. All potentials are referenced versus the saturated calomel electrode (SCE). ${ }^{[b]}$ Separation between the anodic $\left(E^{p a}\right)$ and cathodic peaks $\left(E^{p c}\right)$ of the redox wave $\left(\Delta \mathrm{E}_{\mathrm{p}}=\mathrm{E}^{\mathrm{pa}}-\mathrm{E}^{\mathrm{pc}}\right) .{ }^{[\mathrm{cc}} \operatorname{Sodium}$ salt. ${ }^{[\mathrm{d}]}$ Peak-potential value for irreversible processes. 
The electrochemical data of 3-5, ferrocenecarboxylic acid and 1,1'-ferrocenedicarboxylic acid have been included for comparative purposes [92]. The $\mathrm{CV}$ of the $\mathrm{Zn}_{2} \mathrm{Fe}$ complex $\mathbf{1 1}\left[\mathrm{ClO}_{4}\right.$ ] shows one reversible redox wave at +0.54 $\mathrm{V}$ that can be readily assigned to the oxidation of the ferrocene moiety, since it its absent in the $\mathrm{CV}$ of [ $\left.\mathrm{LZn} \mathrm{n}_{2}(\mathrm{OAc})\right]$ $\left[\mathrm{ClO}_{4}\right]\left(3\left[\mathrm{ClO}_{4}\right]\right)$. Interestingly, the complexation of $\left[\mathrm{CpFe}\left(\mathrm{C}_{5} \mathrm{H}_{4} \mathrm{COO}\right)\right]^{-}$causes an anodic potential shift of $90 \mathrm{mV}$ in the reversible redox wave of the ferrocene moiety. It is assumed that this potential shift results from the electrostatic repulsion (Coulomb) effect between the two $\mathrm{Zn}^{2+}$ ions bonded by the macrocycle and the positively charged ferrocenium centre. Thus complexation of $\left[\mathrm{CpFe}\left(\mathrm{C}_{5} \mathrm{H}_{4} \mathrm{COO}\right)\right]^{-}$by the dipositively charged $\left[\mathrm{LZn}_{2}\right]^{2+}$ unit makes the ferrocenyl group more difficult to oxidize. Curiously, an anodic shift of $\approx 140 \mathrm{mV}$ for the peak potential for the second, irreversible ligandbased oxidation (formally a $\mathrm{RS}^{-} \rightarrow \mathrm{RS}$ transition) [29] that follows the ferrocenyl centred oxidation is also evident. In this case it is the additional positive charge on the ferrocene that causes the thiolate sulfur atoms to be oxidized at a higher potential. The redox-processes for $\mathbf{1 1}\left[\mathrm{ClO}_{4}\right]$ are summarized in Scheme 5.

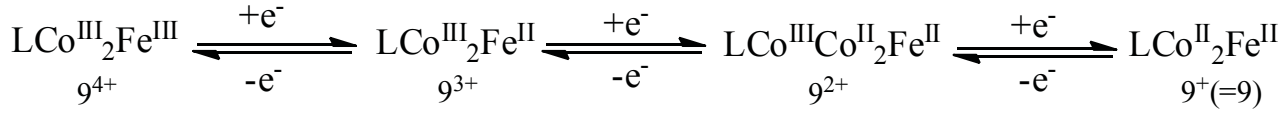

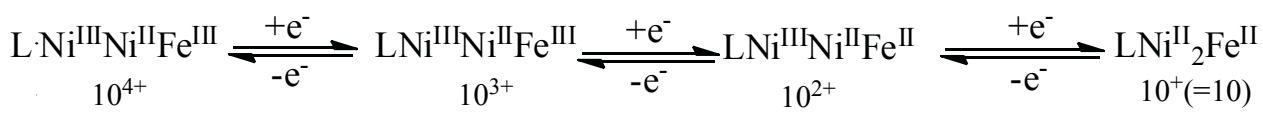

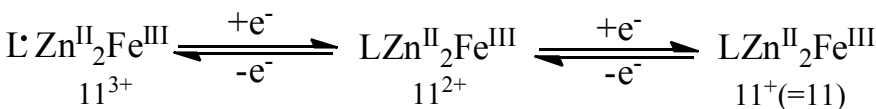

$$
\begin{aligned}
& \left(\mathrm{LCo}_{2}{ }_{2}\right)_{2} \mathrm{Fe}^{\mathrm{II}} \underset{14^{6+}}{\stackrel{+2 \mathrm{e}^{-}}{\rightleftharpoons}}\left(\mathrm{LCo}_{2}{ }_{2}\right)_{2} \mathrm{Fe}^{\mathrm{II}} \underset{14^{4+}}{\stackrel{+2 \mathrm{e}^{-}}{\rightleftharpoons}}\left(\begin{array}{c}
\mathrm{LCo}_{2} \\
\left.2{ }_{2}\right)_{2} \mathrm{Fe}^{\mathrm{II}}
\end{array}\right.
\end{aligned}
$$

Scheme 5. Assignment of redox processes in 9-11 and 14

The $\mathrm{CV}$ of the $\mathrm{Co}_{2} \mathrm{Fe}$ complex 9 exhibits three reversible one-electron redox waves which can be assigned to i) a metal-centered $\mathrm{Co}^{\mathrm{II}} \mathrm{Co}^{\mathrm{II}} \rightarrow \mathrm{Co}^{\mathrm{II}} \mathrm{Co}^{\mathrm{III}}$ oxidation yielding the mixed-valent dication $\left[\mathrm{LCo}^{\mathrm{III}} \mathrm{Co}^{\mathrm{II}}\left(\mathrm{O}_{2} \mathrm{CC}_{5} \mathrm{H}_{4} \mathrm{FeCp}\right]^{2+}\left(\mathbf{9}^{2+}\right)\right.$ at $0.20 \mathrm{~V}$, ii) a metal-centered $\mathrm{Co}^{\mathrm{III}} \mathrm{Co}^{\mathrm{II}} \rightarrow \mathrm{Co}^{\mathrm{III}} \mathrm{Co}^{\mathrm{III}}$ oxidation at $0.59 \mathrm{~V}$ forming tricationic $\left[\mathrm{LCo}_{2}^{\mathrm{III}}\left(\mathrm{O}_{2} \mathrm{C}_{5} \mathrm{H}_{4} \mathrm{FeCp}\right]^{3+}\left(\mathbf{9}^{3+}\right)\right.$, and iii) oxidation of the metalorganic unit generating tetracationic $\left[\mathrm{LCo}_{2}{ }_{2} \mathrm{II}\left(\mathrm{O}_{2} \mathrm{CC}_{5} \mathrm{H}_{4} \mathrm{Fe}^{\mathrm{III}} \mathrm{Cp}\right)\right]^{4+}\left(9^{4+}\right)$ at $0.81 \mathrm{~V}$. These assignments are supported by the electronic absorption spectra of the corresponding di-, tri- and tetracations generated in situ by successive chemical oxidations of $\mathbf{9}^{+}$with $0.5,1.0$, and 1.5 equiv of bromine in acetonitrile solution (Figure 10); the characteristic absorption maxima at 388 and $467 \mathrm{~nm}$ of the ferrocinium ion are not observed before the third oxidation step.

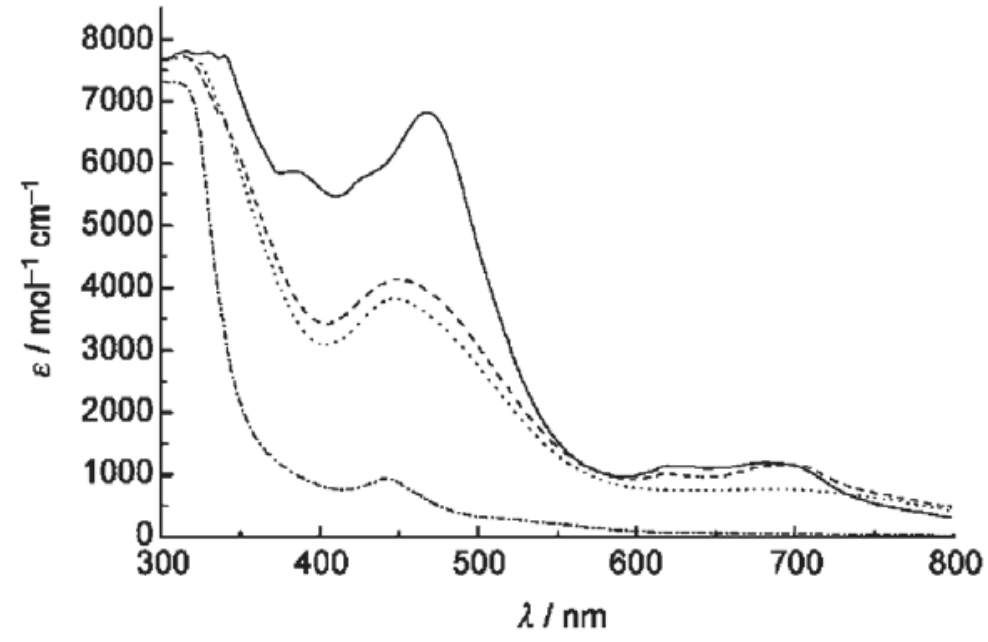

Figure 10. UV/Vis spectra of $9(-\cdot-\cdot), 9^{2+}(\cdots \cdots), 9^{3+}(----)$, and $9^{4+}(-)$ in acetonitrile generated by chemical oxidation of $\left[\mathrm{LCo}_{2}{ }_{2}\left(\mu-\mathrm{O}_{2} \mathrm{CC}_{5} \mathrm{H}_{4} \mathrm{FeCp}\right)\right]\left[\mathrm{ClO}_{4}\right]\left(9\left[\mathrm{ClO}_{4}\right]\right)$ with $0.5,1.0$, and 1.5 equiv of $\mathrm{Br}_{2}$, respectively.

The potential shift for the oxidation of the ferrocenyl unit in $\mathbf{9}^{3+}(\Delta \mathrm{E}=+0.37 \mathrm{~V})$ is significantly larger than in $\mathbf{1 1}^{+}$. The significantly larger shift is likely to be a result of the higher positive charge of the $\left[\mathrm{LCo}_{2}{ }_{2}\right]^{5+}$ fragment to which the $\mathrm{Fe}^{\mathrm{II}}(\mathrm{Cp})\left(\mathrm{C}_{5} \mathrm{H}_{4} \mathrm{COO}^{-}\right)$unit is attached in $\mathbf{9}^{3+}$. 
The $\mathrm{CV}$ of $\mathrm{Ni}_{2} \mathrm{Fe}$ compound $\mathbf{1 0}$ reveals two electrochemically reversible and one irreversible redox waves, which by comparison with the $\mathrm{CV}$ of $\mathbf{5}$ [29] are tentatively assigned to i) a metal-centred $\mathrm{Ni}^{\mathrm{II}} \mathrm{Ni}^{\mathrm{II}} \rightarrow \mathrm{Ni}^{\mathrm{II}} \mathrm{Ni}^{\mathrm{III}}$ oxidation yielding the mixed-valent dication $\left[\mathrm{LNi}^{\mathrm{III}} \mathrm{Ni}^{\mathrm{II}}\left(\mathrm{O}_{2} \mathrm{CC}_{5} \mathrm{H}_{4} \mathrm{Fe}^{\mathrm{II}} \mathrm{Cp}\right)\right]^{2+}\left(\mathbf{5}^{2+}\right)$ at $0.53 \mathrm{~V}$, ii) the oxidation of the metal organic unit forming $\left[\mathrm{LNi}^{\mathrm{III}} \mathrm{Ni}^{\mathrm{II}}\left(\mathrm{O}_{2} \mathrm{CC}_{5} \mathrm{H}_{4} \mathrm{Fe}^{\mathrm{II}} \mathrm{Cp}\right)\right]^{3+}\left(\mathbf{5}^{3+}\right)$ at $0.71 \mathrm{~V}$, and iii) the oxidation of the thiophenolate sulfur atoms yielding a nickel bound thiyl radical at $1.59 \mathrm{~V}$. Anodic shifts in the second and third redox waves are clearly discernible, confirming the above findings that the electron transfer events of the ferrocenyl moiety and the binuclear subunit influence one another. The fact that the potential shifts are not so pronounced than in $\mathbf{9}$ is in good agreement with the smaller positive charges of the participating species. It should be noted that all oxidation products of $\mathbf{9}$ and $\mathbf{1 0}$ are only stable on the time scale of a cyclic voltammetry experiment. Attempts to prepare these compounds by electrochemical or chemical oxidation led to unidentified decomposition products. Thus, while some of the above oxidations appear electrochemically reversible, they are all chemically irreversible.

Of the tetranuclear complexes, only complex $\mathbf{1 4}\left[\mathrm{ClO}_{4}\right]_{4}$ had sufficient solubility (due to its higher charge) to examine its electrochemical properties by cyclic voltammetry. The CV shows two quasi-reversible redox waves. On the basis of the crystal structure of $\mathbf{1 4}\left[\mathrm{ClO}_{4}\right]_{4}$, the first redox wave at $0.22 \mathrm{~V}$ can be assigned to a two-electron reduction of $\mathbf{1 4}^{4+}$ yielding the fully-reduced $\mathrm{Co}_{4}{ }_{4} \mathrm{Fe}$ form $\mathbf{1 4}^{2+}$ (which is assumed to be identical with $\mathbf{1 2}$ ). The other wave at $0.53 \mathrm{~V}$ can be attributed to a metal-centred two-electron oxidation process yielding the fully oxidized $\mathrm{Co}_{4}^{\mathrm{III}}{ }_{4} \mathrm{Fe}$ form $\left[\left(\mathrm{LCo}_{2}\right)_{2}(\mathrm{Fe}(\mathrm{Cp}))\right]^{6+}\left(\mathbf{1 4}^{6+}\right)$. The observed potential values are almost identical with those in 4 [67], indicating that the oxidation/ reduction processes at one $\left[\mathrm{LCO}_{2}\right]$ unit do not influence the ones that occur at the other. In other words, the two dinuclear cobalt(II) subunits behave as two independent redox-groups. That is fully consistent with the large distance between the two subunits and the fact that the electrostatic (Coulomb) interactions decrease rapidly with increasing distance between the redox sites. The redox wave for the oxidation of the $\left[\mathrm{Fe}\left(\mathrm{C}_{5} \mathrm{H}_{4} \mathrm{CO}_{2}\right)_{2}\right]^{2-}$ unit in $\mathbf{1 4}$ could not be detected. We assume that it is obscured by the redox waves at $0.53 \mathrm{~V}$.

There have been many reports in the literature that a charged subunit can influence the redox properties of an adjacent ferrocene group [93] ; to our knowledge, complexes 9-11 represent the first examples for a system in which the redox properties of a ferrocenecarboxylate-based ligand is modified by dinuclear aminethiophenolate complexes.

The magnetic properties of the pentanuclear $\mathrm{Ni}_{4} \mathrm{Fe}$ complex $13\left[\mathrm{BPh}_{4}\right]_{2}$ were examined in view of literature reports that conjugated dicarboxylate ligands can mediate long-range magnetic exchange interactions [45]. Figure 11 displays the temperature dependence of the effective magnetic moment for $\mathbf{1 3}\left[\mathrm{BPh}_{4}\right]_{2}$. The effective magnetic moment increases from $6.88 \mu_{\mathrm{B}}$ at $295 \mathrm{~K}$ to a maximum value of $7.70 \mu_{\mathrm{B}}$ at $25 \mathrm{~K}$. On lowering the temperature further the magnetic moment decreases to $7.08 \mu_{\mathrm{B}}$ at $2 \mathrm{~K}$. Although the effective magnetic moment at $25 \mathrm{~K}$ is smaller than expected for the spin-only value of $9.84 \mu_{\mathrm{B}}$ for $\mathrm{S}_{\mathrm{T}}=4$ resulting from the ferromagnetic coupling of four $\mathrm{Ni}^{\mathrm{II}}$ ions $\left(\mathrm{S}_{\mathrm{i}}=1, \mathrm{~g}=2.20\right)$, it is larger than the value of $6.22 \mu_{\mathrm{B}}$ calculated for four noninteracting $\mathrm{Ni}^{\mathrm{iI}}$ ions. This behaviour indicates the presence of weak ferromagnetic exchange interactions between the $\mathrm{Ni}^{\mathrm{II}}$ ions in the binuclear subunits but negligible - if any coupling across the metallocene dicarboxylate bridge. Considering the long distance between the nickel(II) ions, this is not surprising.

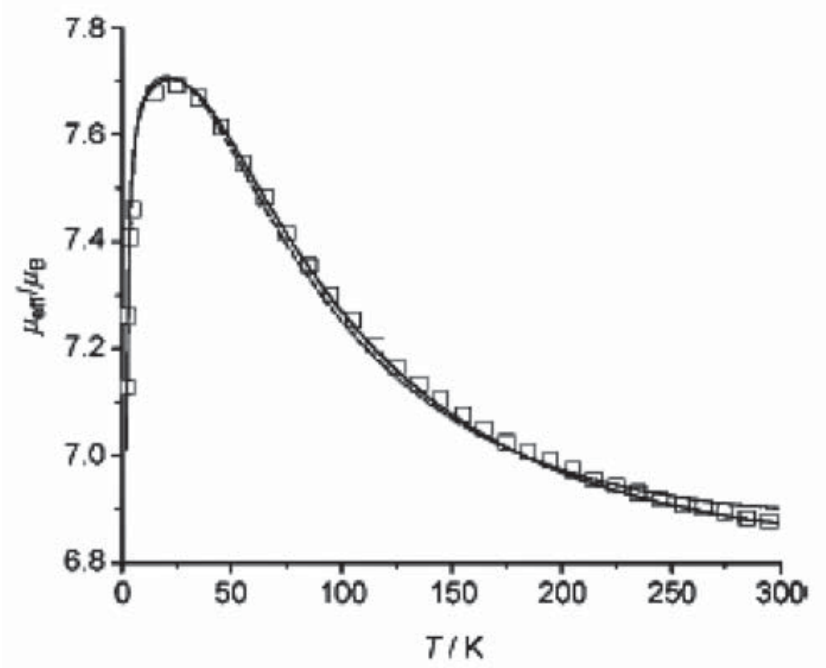

Figure 11. Temperature dependence of $\mu_{\text {eff }}$ (per tetranuclear complex) for $13\left[\mathrm{BPh}_{4}\right]_{2}$. The full line represents the best theoretical fit. The dashed line represents the best fit to the dimer model. 


\section{Functionalized naphthalene diimide as a bifunctional linker}

We and others have been working with naphthalene diimides as a suitable class of chemically robust redox- and photo-active units with which to explore molecular electronic applications [94, 95].

The naphthalene diimides are a compact, electron-deficient class of aromatic compounds that allow further finetuning of their optical properties (absorbance and emission) via suitable core functionalization [95]. The consideration that naphthalene diimides can act as ideal components for the creation of supramolecular functional materials has transpired as a result of their more desirable electronic and spectroscopic properties relative to pyromellitic diimides and better fabrication properties than the perylene diimide dyes, the latter being a result of their enhanced solubility properties. Naphthalene diimides (NDI) undergo single reversible one-electron reduction (chemically and electrochemically) at modest potentials (NDI: $\mathrm{E}_{\text {red }}^{1} \approx 1.1 \mathrm{~V}$ vs. $\mathrm{Fc} / \mathrm{Fc}^{+}$) to form stable radical anions in high yield [96]. They are seen as attractive redox-active units because of their electronic complementarity to ubiquinones [97] which make them excellent components for studying photoinduced electron transfer [98]. Here we examine the interplay of a binucleating nickel(II) cavitand $\left[\mathrm{LNi}_{2}(\mu-\mathrm{Cl})\right]\left[\mathrm{ClO}_{4}\right](\mathbf{1})$ [1] with a naphthalene diimide 16 bearing two $\beta$-alanyl groups [99, 100] (Scheme 6).

To our knowledge, complex 15 represents the first example of a supramolecular ensemble containing dinuclear amine-thiolate complexes and redox-active organic components within the same molecule.

Reaction of 1 with half an equivalent of $\mathbf{1 6}$ with $\mathrm{NEt}_{3}$ in $\mathrm{MeOH}$ at r.t. leads to the immediate formation of a green solution. After the addition of a ten-fold excess of $\mathrm{LiClO}_{4}$ a green microcrystalline solid, characterized as the 2:1 complex $\mathbf{1 5}\left[\mathrm{ClO}_{4}\right]_{2}$, is obtained in $72 \%$ yield. The perchlorate salt of $\mathbf{1 5}^{2+}$ is an air-stable solid that is readily soluble in polar aprotic solvents such as $\mathrm{N}, \mathrm{N}$-dimethylformamide, dichloromethane and acetonitrile, but virtually insoluble in methanol and water. The electrospray ionization mass spectrum (ESI-MS, positive mode)

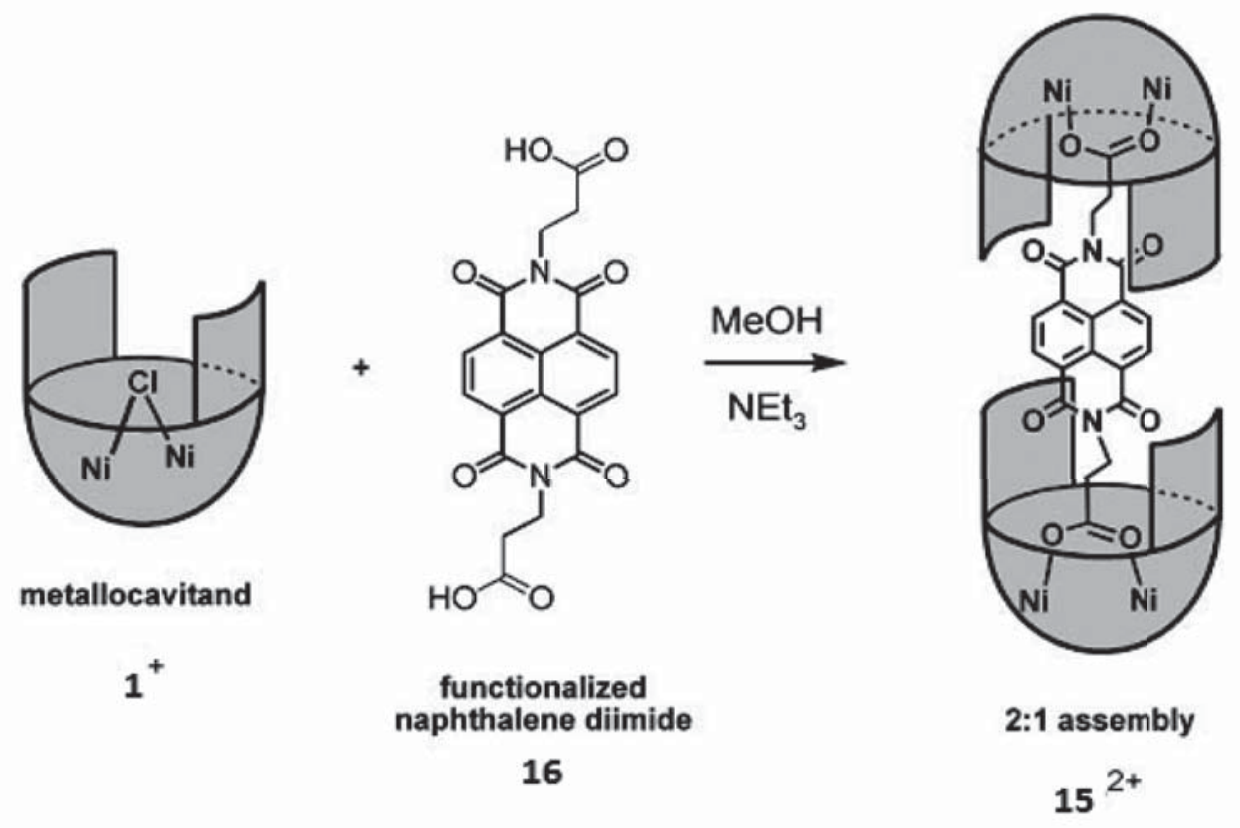

Scheme 6. Schematic representation of the encapsulation of the di-functionalised naphthalene diimide 16 by a binucleating metallocavitand 1 to yield the complex $15\left[\mathrm{ClO}_{4}\right]_{2}$.

of a dilute $\mathrm{CH}_{2} \mathrm{Cl}_{2}$ solution of $\mathbf{1 5}\left[\mathrm{ClO}_{4}\right]_{2}$ exhibits a molecular ion peak with the correct isotopic distribution for the dication $\mathbf{1 5}^{2+}(\mathrm{m} / \mathrm{z}=989.36)$. Two prominent vibration bands are seen in the $\mathrm{IR}$, as in other carboxylato-bridged $\mathrm{Ni}_{2}$ complexes of $(\mathrm{L})^{2-}$, at 1583 and $1423 \mathrm{~cm}^{-1}[65,67]$. These are assigned to the antisymmetric and symmetric carboxylate stretching modes, respectively, of a $\mu_{1,3}$-bridging carboxylate function. The $v(\mathrm{CO})$ stretching frequencies of the carboxamide functions of $[\mathbf{1 6}-2 \mathrm{H}]^{2-}$ are also clearly visible at 1706 and $1669 \mathrm{~cm}^{-1}$.

The dual coordination mode of the naphthalene diimide unit is further demonstrated by UV/Vis spectroscopy. The UV/Vis spectrum of a solution of $\mathbf{1 5}\left[\mathrm{ClO}_{4}\right]_{2}$ in $\mathrm{CH}_{2} \mathrm{Cl}_{2}$ is displayed in Figure 12 and that of $\left[\mathrm{LNi}_{2}(\mathrm{OAc})\right]\left[\mathrm{ClO}{ }_{4}\right]$ $\mathbf{5}\left[\mathrm{ClO}_{4}\right]$ is shown for comparison. Complex $\mathbf{1 5}^{2+}$ reveals five well-resolved UV bands at 272, 306, 336, 360 and $380 \mathrm{~nm}$, the former three of which are attributable to the $\pi-\pi^{*}$ transitions within the thiophenolate units of the $\left[\mathrm{Ni}_{2} \mathrm{~L}\right]^{2+}$ fragments. Their intensity is approximately twice as large as those of the model compound $\mathbf{5}^{+}$, which is in good agreement with the formulation of compound $\mathbf{1 5}^{2+}$ as a $2: 1$ complex. 


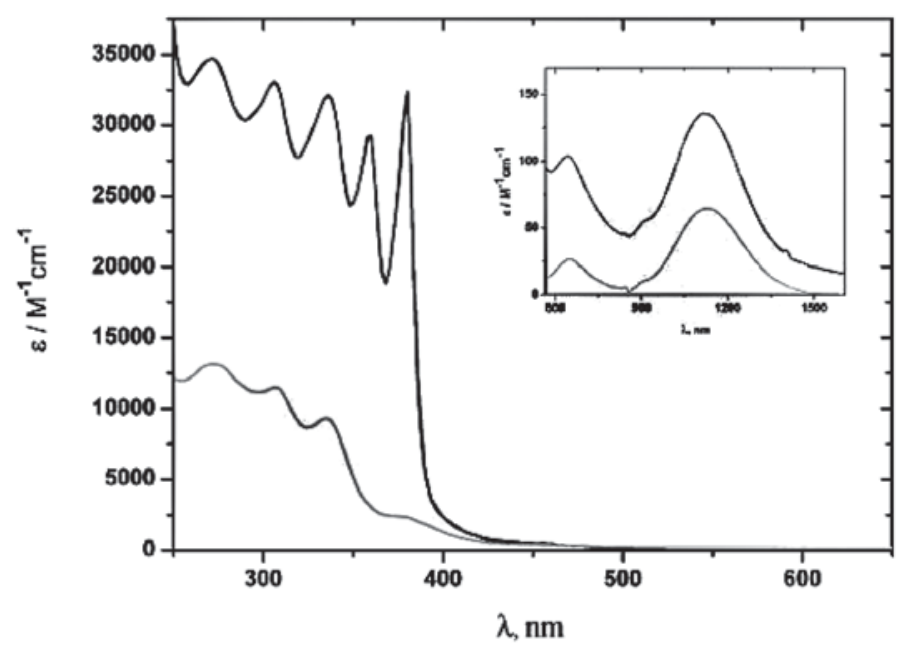

Figure 12. Electronic absorption spectra of $15\left[\mathrm{ClO}_{4}\right]_{2}$ (black) and model $5\left[\mathrm{ClO}_{4}\right]\left(\right.$ grey) in $\mathrm{CH}_{2} \mathrm{Cl}_{2}$ solution (sample concentration $=10^{-4} \mathrm{M}$ ). The inset shows the absorptions of $15\left[\mathrm{ClO}_{4}\right]_{2}$ and $5\left[\mathrm{ClO}_{4}\right]$ attributed to weak d-d absorptions (sample concentration $=10^{-3} \mathrm{M}$ ).

The low energy bands at 360 and $380 \mathrm{~nm}$ which are typical for naphthalene diimides [96] further confirm the identity of complex $\mathbf{1 5}^{2+}$. TheUV/Vis spectrum also reveals two weak $\mathrm{d}-\mathrm{d}$ absorption bands at 644 and $1122 \mathrm{~nm}$ typical of octahedral $\mathrm{Ni}^{\text {II }}$ in an $\mathrm{N}_{3} \mathrm{~S}_{2} \mathrm{O}^{\text {carboxylate }}$ environment. The observed values closely compare with those of $\mathbf{5}^{+}$(see inset in Fig. 12) again consistent with pseudo-octahedral $\mathrm{N}_{3} \mathrm{~S}_{2} \mathrm{O}$ coordination environments around the metal atoms. All these findings strongly indicate that the tetranuclear complex $15^{2+}$ retains its integrity in solution.

To determine whether $\mathbf{1 5}^{2+}$ exhibits electron transfer events due to the NDI unit and the $\left[\mathrm{Ni}_{2} \mathrm{~L}\right]^{2+}$ groups, cyclic voltammetric studies have been carried out on $\mathbf{1 5}\left[\mathrm{ClO}_{4}\right]_{2}$ in DMF solution using $0.10 \mathrm{M}\left[{ }^{\mathrm{n}} \mathrm{Bu}_{4} \mathrm{~N}\right]\left[\mathrm{PF}_{6}\right]$ as the supporting electrolyte (Fig. 13). The $\mathrm{CV}$ of the $\mathrm{Ni}_{4}$ complex $\mathbf{1 5}\left[\mathrm{ClO}_{4}\right]_{2}$ shows three redox waves at -1.62 ,

-1.04 and $0.15 \mathrm{~V}$, respectively, vs. ferrocenium /ferrocene $\left(\mathrm{Fc}^{+} / \mathrm{Fc}\right)$. The processes at -1.04 and $-1.62 \mathrm{~V}$ correspond to the reduction of the dication $15^{2+}$ to $15^{+}$(bearing the radical anion $16^{-}$) and the reduction of $15^{+}$to neutral 15 (bearing the doubly reduced NDI ligand), respectively. Upon reduction of $\mathbf{1 5}^{2+}$ by either electrochemical or chemical means $\left(\mathrm{Na}_{2} \mathrm{~S}_{2} \mathrm{O}_{4} / \mathrm{H}_{2} \mathrm{O}\right)$ the colour of the complex changes to deep mauve which (in the absence of air) persists in solution over $3 \mathrm{~h}$ indicative of radical anion formation. The redox wave located at $0.15 \mathrm{~V}$ on the other hand is tentatively assigned to a two-electron metal-centered $\mathrm{Ni}^{\mathrm{II}} \mathrm{Ni}^{\mathrm{II}} \rightarrow \mathrm{Ni}^{\mathrm{II}} \mathrm{Ni}^{\mathrm{II}}$ oxidation yielding the mixed-valent tetrametallic tetracation $\left[\left(\mathrm{Ni}^{\mathrm{II}} \mathrm{Ni}^{\mathrm{II}} \mathrm{L}\right)_{2}(\mathbf{1 6})\right]^{4+}\left(\mathbf{1 5}^{4+}\right)$. The redox-wave for the oxidation of the tetracation $\mathbf{1 5}^{4+}$ to the hexacation $\mathbf{1 5}^{6+}$ (formally a $\mathrm{Ni}^{\mathrm{II}} \mathrm{Ni}^{\mathrm{III}} \rightarrow \mathrm{Ni}{ }^{\mathrm{II}} \mathrm{Ni}{ }^{\mathrm{III}}$ process as seen for complex $\mathbf{5}\left[\mathrm{ClO}_{4}\right]$ ) could not be detected. We assume that it is obscured by the redox-waves associated with the oxidation of the solvent.

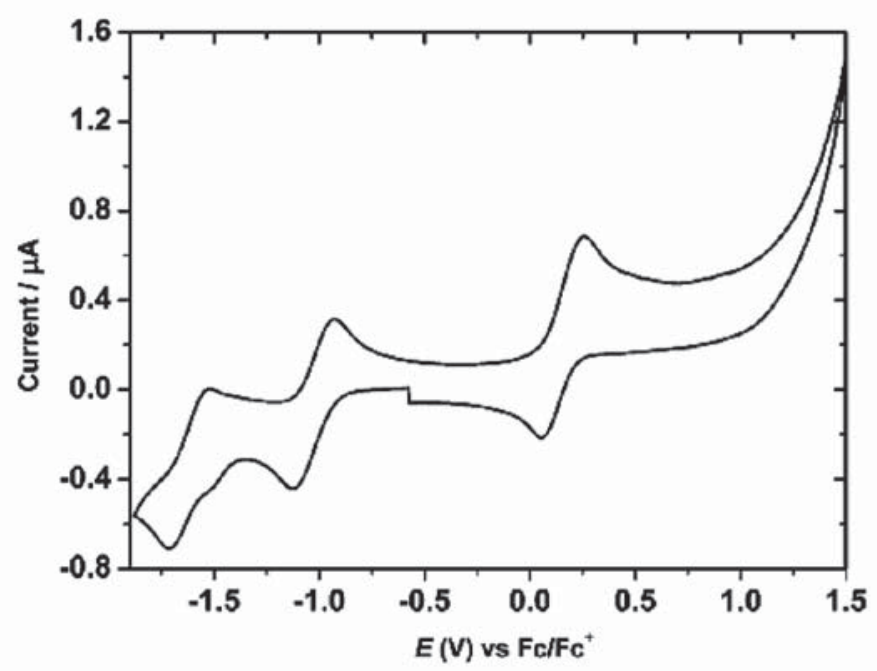

Figure 13. Cyclic voltammogram of $15\left[\mathrm{ClO}_{4}\right]_{2}$ in DMF at 295K. Experimental conditions: $\left[15\left(\mathrm{ClO}_{4}\right)_{2}\right]=$ $10^{-3} \mathrm{M}$, Pt-disk working electrode, $\mathrm{Ag}$ wire reference electrode, $\left.0.1 \mathrm{M}^{\mathrm{n}} \mathrm{Bu} \mathrm{u}_{4} \mathrm{~N}\right]\left[\mathrm{PF}_{6}\right]$, scan rate $=200 \mathrm{mV} \mathrm{s}^{-1}$. 
The redox-processes are summarised in Scheme 7.

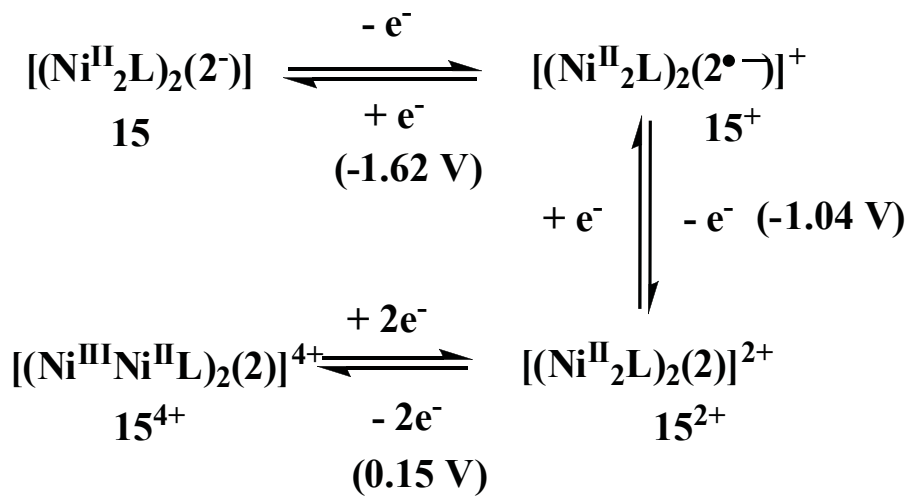

Scheme 7. Assignment of redox processes for $15\left[\mathrm{ClO}_{4}\right]_{2}$.

The observed potentials for the reduction of the naphthalene diimide ligand $\mathbf{1 6}$ are ca. $100 \mathrm{mV}$ more negative than those reported for other $\mathrm{N}$-alkylated naphthalene diimides [95]. Though there are many factors that could contribute to this significant effect, a simplistic thermodynamic view would argue that the influence of the aromatics within the cavitand structure on the NDI upon encapsulation is a strong contributor. The single peak value of $0.15 \mathrm{~V}$ measured for the $\mathrm{Ni}^{\mathrm{II}} \rightarrow \mathrm{Ni}^{\mathrm{III}}$ oxidation steps is almost identical to that observed for the model $5\left[\mathrm{ClO}_{4}\right](\mathrm{E}=0.11 \mathrm{~V} \mathrm{vs}$. Fc $/ \mathrm{Fc})$ [29], indicating that the oxidation/reduction process on one $\left[\mathrm{Ni}_{2} \mathrm{~L}\right]$ unit does not influence the processes that occur at the other site [75]. In other words, the two dinuclear nickel(II) subunits behaveas two independent redox-groups. This observation is consistent with the large distance of ca. $19 \AA$ between the two subunits (see Fig. 14(a)) and the fact that the electrostatic (Coulombic) interactions decrease rapidly with increasing distance between two redox-sites.

The radical anion of the NDI within $\mathbf{1 5}^{+}$is characterised by a set of intense and characteristic visible and nearinfrared (NIR) absorption bands. Thus, the electronic spectrum of a solution of $\mathbf{1 5}^{+}$in DMF (generated by reduction of $\mathbf{1 5}^{2+}$ with an aqueous $\mathrm{Na}_{2} \mathrm{~S}_{2} \mathrm{O}_{4}$ solution) shows bands at 270 (50236), 283 (26840), 329 (28917), 373sh (1072), 400sh (8360), 474 (31586), 607 (9019), $682(4738)$ and $756 \mathrm{~nm}\left(6618 \mathrm{M}^{-1} \mathrm{~cm}^{-1}\right)$. Similar values have been reported for other NDI radicals [95].

(a)

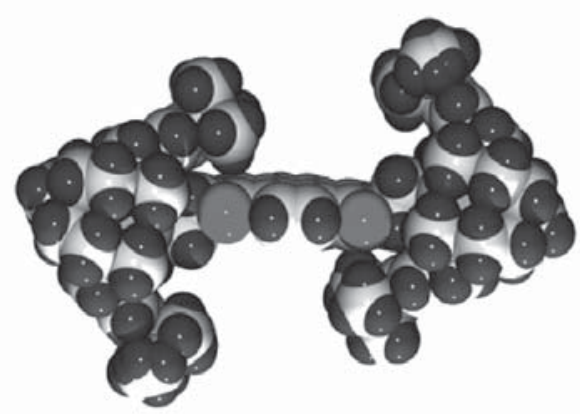

(b)

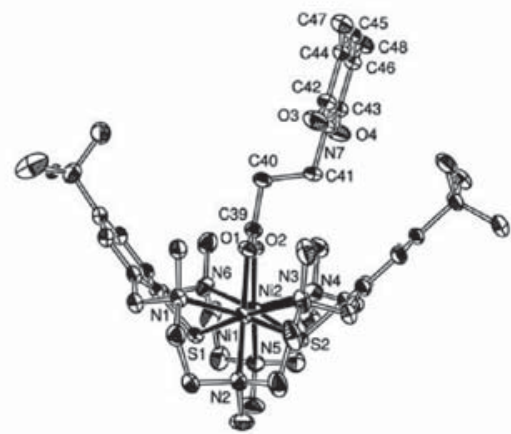

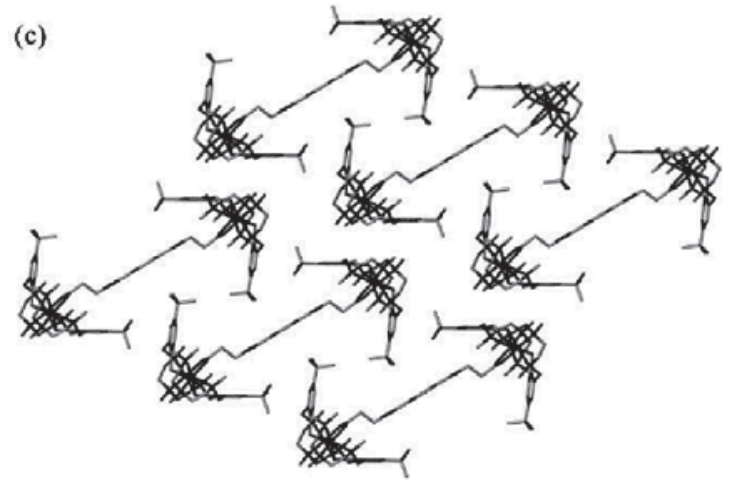

Figure 14. (a) van derWaals representation of the molecular structure of the dication $15^{2+}$ in crystals of $15\left[\mathrm{BPh}_{4}\right]_{2} \cdot$ (b) Asymmetric unit of $15^{2+}$ with thermal ellipsoids drawn at the $30 \%$ probability level, hydrogen atoms and MeCN solvent are omitted for clarity. (c) Packing of individual molecules in the crystal lattice of $15\left[\mathrm{BPh}_{4}\right]_{2}\left(\mathrm{BPh}_{4}{ }^{-}\right.$anions and solvent acetonitrile molecules are omitted for clarity). 
The composition of the assembly as $\mathbf{1 5}^{2+}$ was confirmed by a single-crystal X-ray structure determination, as the tetraphenylborate salt $\mathbf{1 5}\left[\mathrm{BPh}_{4}\right]_{2}$ (prepared by salt metathesis of $\mathbf{1 5}\left[\mathrm{ClO}_{4}\right]_{2}$ with $\mathrm{NaBPh}_{4}$ ). Crystals of $\mathbf{1 5}\left[\mathrm{BPh}_{4}\right]_{2} \cdot \mathrm{xCH}_{3} \mathrm{CN}$ suitable for X-ray crystallography were grown by recrystallisation from MeCN. Fig. 14 displays a van der Waals representation of the centrosymmetric dication $\mathbf{1 5}$ formed within a triclinic crystal with space group $\mathrm{P} \underline{1}$. The dicarboxylate acts as a tetradentate bridging ligand joining two dinuclear $\left[\mathrm{LNi}^{\mathrm{II}}{ }_{2}\right]^{2+}$ fragments through its carboxylate functions. Each $\mathrm{Ni}$ atom is thus surrounded in a highly distorted octahedral fashion by two sulfur atoms and three nitrogen atoms from the supporting ligand $\mathrm{L}^{2-}$, and one oxygen atom from the carboxylate groups of $[\mathbf{1 6}-2 \mathrm{H}]^{2-}$.

The macrocycle assumes a rigid bowl-shaped conformation very similar to that found for $\left[\mathrm{Ni}_{2} \mathrm{~L}(\mu-\mathrm{OAc})\right]\left[\mathrm{ClO}_{4}\right]$ (5) [29]. As a consequence, the $\left[\mathrm{Ni}_{2} \mathrm{~L}\right]^{2+}$ subunits in $\mathbf{1 5}$ and $\mathbf{5}$ are structurally very similar, and the $\mathrm{Ni}-\mathrm{N}$ and $\mathrm{Ni}-\mathrm{S}$ distances lie within very narrow ranges. The NDI ligand assumes a planar conformation and the $\mathrm{Ni}_{2} \mathrm{O}_{2}$ planes are only slightly folded with respect to the NDI plane (folding angle $=15.1^{\circ}$ ). The NDI unit is not coplanar with the aromatic rings of the cavitand, the folding angles between the planes of the two aromatic rings of the cavitand and the plane through the NDI unit being $31.8^{\circ}$ and $53.9^{\circ}$, respectively. The $\mathrm{Ni} \cdots \mathrm{Ni}$ distance of 3.481(1) $\AA$ is practically the same as that in 5 . The distance between the center of the $\mathrm{Ni} \cdots \mathrm{Ni}$ axes of the binuclear subunits are amounts to 19.010(1) $\AA$.

Complex 15 is unique in the sense that its naphthalene diimide coligand is included within the two metallocavitands. To the best of our knowledge, this is the first structural report of such an inclusion complex. In contrast to 'free' NDI compounds, no $\boldsymbol{\pi}-\boldsymbol{\pi}$-stacking interactions involving the NDIs are present in $\mathbf{1 5}$, a fact attributable to the steric shielding of the $\left[\mathrm{Ni}_{2} \mathrm{~L}\right]^{2+}$ units. This feature is no doubt responsible for the enhanced solubility of the complex $\mathbf{1 5}$ over 16. Furthermore, limiting the ability for NDIs to stack has important implications for their use in molecular electronics by limiting aggregation and hence the excimer emission found in many systems [101-103].

The structure is stabilised by intermolecular $\mathrm{CH}^{\cdots} \pi$ interactions as indicated by relatively short distances between

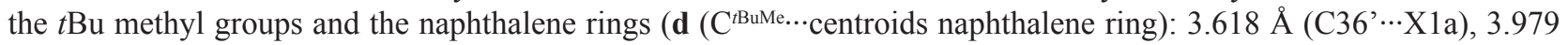

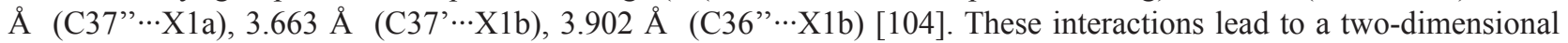
interdigitated packing of the molecules as shown in Figure 14(c). The shortest intermolecular Ni $\cdots \mathrm{Ni}$ distance is at 7.470(1) $\AA$. The structure lacks any intermolecular or intramolecular $\boldsymbol{\pi}-\boldsymbol{\pi}$ stacking interactions. The closest distances between the centre of the NDI unit and the centre of the aromatic rings are 7.633 and $10.018 \AA$, respectively. The $\mathrm{BPh}_{4}{ }^{-}$counterions are well separated from the dication $\mathbf{1 5}^{2+}$.

\section{Conclusions}

In summry, a series of novel tri-, tetra- and pentanuclear complexes composed of dinuclear $\mathrm{LM}_{2}$ units $(\mathrm{M}=\mathrm{Co}$, $\mathrm{Ni}, \mathrm{Zn} ; \mathrm{L}^{2-}=$ represents a macrocyclic hexaazadithiophenolate ligand) and ferrocenecarboxylate $\left(\mathrm{CpFeC}_{5} \mathrm{H}_{4} \mathrm{CO}_{2}^{-}\right)$, 1,1'-ferrocenedicarboxylate $\left(\mathrm{Fe}\left(\mathrm{C}_{5} \mathrm{H}_{4}-\mathrm{CO}_{2}\right)_{2}{ }_{2}{ }^{2-}\right.$, acetylenedicarboxylate, terephthalate, isophthalate, and naphthalene diimide dicarboxylate groups is reported. The complexes, have been synthesized and characterised by UV/Vis-, IRspectroscopy, and X-ray crystallography. Each dicarboxylate dianion acts as a quadridentate bridging ligand linking two bioctahedral $\mathrm{LM}_{2}$ units via $\mu_{1,3}$-bridging carboxylate functions to generate discrete dications with a central $\mathrm{LM}_{2}\left(\mathrm{O}_{2} \mathrm{C}-\right.$ $\left.\mathrm{R}-\mathrm{CO}_{2}\right) \mathrm{M}_{2} \mathrm{~L}$ core. The structures differ mainly in the distance between the center of the $\mathrm{Ni} \cdots \mathrm{Ni}$ axes of the isostructural $\mathrm{LNi}_{2}$ units $\left(8.841(1) \AA\right.$ in $\mathbf{6}\left[\mathrm{BPh}_{4}\right]_{2}, 10.712(1)$ in $7\left[\mathrm{BPh}_{4}\right]_{2}$, and $9.561(1)$ in $\left.\mathbf{8}\left[\mathrm{BPh}_{4}\right]_{2}\right)$ and the tilting angle between the two $\mathrm{Ni}_{2} \mathrm{O}_{2}$ planes $\left(86.3^{\circ}\right.$ in $6\left[\mathrm{BPh}_{4}\right]_{2}, 58.2^{\circ}$ in $7\left[\mathrm{BPh}_{4}\right]_{2}, 20.9^{\circ}$ in $\left.8\left[\mathrm{BPh}_{4}\right]_{2}\right)$. Magnetic susceptibility measurements on the complexes over the range $2.0-295 \mathrm{~K}$ reveal the presence of weak ferromagnetic exchange interactions between the $\mathrm{Ni}^{\mathrm{II}}$ ions within the dinuclear subunits with values for the magnetic exchange constant $J_{1}$ of $23.10,18.06$, and $14.16 \mathrm{~cm}^{-1}$ for $6\left[\mathrm{BPh}_{4}\right]_{2}, 7\left[\mathrm{BPh}_{4}\right]_{2}$, and $\mathbf{8}\left[\mathrm{BPh}_{4}\right]_{2}$, respectively $\left(\mathrm{H}=-2 J \mathrm{~S}_{1} \mathrm{~S}_{2}\right)$. The magnitude of the exchange interaction $J_{2}$ across the dicarboxylate bridges is in all cases less than $0.1 \mathrm{~cm}^{-1}$, suggesting that no significant interdimer exchange coupling occurs in $6\left[\mathrm{BPh}_{4}\right]_{2}-8\left[\mathrm{BPh}_{4}\right]_{2}$.

The first members of a new class of polynuclear transition metal complexes composed of classical [ $\left.\mathrm{LM}_{2}\right]$ units $(\mathrm{M}=\mathrm{Co}, \mathrm{Ni}, \mathrm{Zn})$ and ferrocenylcarboxylate groups were synthesised and characterized. Mixed-valent $\left[\left(\mathrm{LCo}^{\mathrm{II}} \mathrm{Co}^{\mathrm{III}}\right)_{2}{ }^{-}\right.$ $\left.\left(\mathrm{O}_{2} \mathrm{CC}_{5} \mathrm{H}_{4}\right)_{2} \mathrm{Fe}\right]^{4+}(14)$ was prepared by oxidation of 12 with bromine. X-ray crystal determination of complexes $9\left[\mathrm{BPh}_{4}\right]$, $10\left[\mathrm{BPh}_{4}\right], \mathbf{1 2}\left[\mathrm{BPh}_{4}\right]_{2}, \mathbf{1 3}\left[\mathrm{BPh}_{4}\right]_{2}$, and $\mathbf{1 4}\left[\mathrm{ClO}_{4}\right]_{4}$ show, that the ferrocenyl carboxylates act as bidentate $(\mathbf{9}, \mathbf{1 0})$ or bisbidentate (12-14) bridging ligands towards one or two bioctahedral $\mathrm{LM}_{2}$ subunits, respectively. The structures are retained in solution as indicated by NMR spectroscopic studies on the diamagnetic ferrocenylcarboxylate $\left[\mathrm{ClO}_{4}\right]$. All complexes were found to exhibit a rich redox chemistry. Complexation of the ferrocenylcarboxylates by the $\mathrm{LM}_{2}$ fragments results in large potential shifts of the ferrocenyl-centred redox process. The redox processes of the $\mathrm{LM}_{2}$ units are also affected upon complex formation, showing that the electron transfer events of the ferrocenyl moiety and the binuclear subunit influence one another. In 14, however, the two dinuclear cobalt(II) subunits behave as two independent redox-groups owing to the large distance between them. Additionally, we found that the magnetic properties in the pentanuclear $\mathrm{Ni}_{4} \mathrm{Fe}$ complex 13 are based on the ferromagnetic exchange interactions between the $\mathrm{Ni}^{\mathrm{II}}$ ions in the binuclear subunits. The coupling across the metallocene dicarboxylate bridge is negligible. These results can now be used as a guide for further studies aimed at the synthesis of polynuclear complexes with novel electronic and magnetic properties. 
The first member of a new class of inclusion complex composed of encapsulating metallocavitands and naphthalene diimide units 15 were found to exhibit a rich redox chemistry. Complexation of the naphthalene diimide dicarboxylate 16 by the $\mathrm{Ni}_{2} \mathrm{~L}$ fragments results in a cathodic potential shift of the diimide-centered redox process. The two dinuclear nickel (II) subunits behave as two independent redox-groups owing to the large distance of ca. $19 \AA$ between them. These results can now be used as a guide for further studies aimed at a more complete encapsulation of the naphthalene diimide subunits, its photochemical properties and future developments in optoelectronics.

\section{Acknowledgements}

The author is thankful to Professor B.Kersting (University of Leipzig, Germany) for providing facilities of work in his research group and financial support.

\section{References}

[1]. Lozan, V.; Loose, C.; Kortus J.; Kersting, B. Coord. Chem. Rev., 2009, 253, 2244-2260.

[2]. Kersting, B. Z. Anorg. Allg. Chem., 2004, 630, 765-780.

[3]. Cotton, F.A.; Wilkinson, G.; Murillo, C.A.; M. Bochmann, M. Advanced Inorganic Chemistry, 6th ed., John Wiley \& Sons, Weinheim, 1999, p. 486.

[4]. a) Cotton, F.A.; Donahue, J.P.; Murillo, C.A. J. Am. Chem.Soc. 2003, 125, 5436-5450.

b) Cotton, F.A.; Donahue, J.P.; Murillo, C.A.; Perez, L.M. J. Am. Chem. Soc. 2003, 125, 5486-5492.

[5]. A) Eddaoudi, M.; Moler, D.B.; Li, H.; Chen, B.; Reineke, T.M.; O’Keefe, M.; Yaghi, O.M. Acc. Chem. Res. 2001, 34, 319-330; b) Eddaoudi, M.; Kim, J.; Wachter, J.B.; Chae, H.K.; O’Keefe, M.; Yaghi, O.M. J. Am. Chem. Soc. 2001, 123, 4368-4369; c) Rowsell, J. L. C.; Milward, A.R.; Park, K.S.; Yaghi, O.M. J. Am. Chem. Soc. 2004, 126, 5666-5667; d) Barton, T.J.; Bull, L.M.; Klemperer, W.G.; Loy, D.A.; McEnaney, B.; Misono, M.; Monson, P.A.; Pez, G.; Scherer, G.W.; Vartuli, J.C.; Yaghi, O.M. Chem. Mater. 1999, 11, 2633-2656.

[6]. Rao, C. N. R.; Natarajan, S.; Choudhury, A.; Neeraj, S.; Ayi, A.A. Acc. Chem. Res. 2001, 34, 80-87.

[7]. Moulton, B.; Zaworotko, M.J. Chem. Rev. 2001, 101, 1629-1658.

[8]. Kitagawa, S.; Kitaura, R.; Noro, S. Angew. Chem. 2004, 116, 2388-2430; Angew. Chem. Int. Ed. 2004, 43, 2334-2375.

[9]. Kitagawa, S.; Noro, S.; Nakamura, T. Chem. Commun. 2006, 701-707.

[10]. Kahn, O. Molecular Magnetism, VCH, Weinheim, 1993.

[11]. Magneto-Structural Correlation in Exchange Coupled Systems (Eds.: Willet, R.D.; Gatteschi, D.; Kahn, O.), NATO ASI Series, Redidel, Dordrecht, 1985.

[12]. Miller, J.S.; Epstein, A.J. Angew. Chem. 1994, 106, 399-432; Angew. Chem. Int. Ed. Engl. 1994, 33, $385-418$.

[13]. Julve, M.; Faus, J.; Verdaguer, M.; Gleizes, A. J. Am. Chem. Soc. 1984, 106, 8306-8308.

[14]. a) Girerd, J.J.; Kahn, O.; Verdaguer, M. Inorg. Chem. 1980, 19, 274-276; b) Bakalbassis, E.; Bergerat, P.; Kahn, O.; Jeannin, S.; Jeannin, Y.; Dromzee, Z.; Guillot, M. Inorg. Chem. 1992, 31, 625-631; c) Kahn, O.; Martinez, C.J. Science 1998, 279, 44-48.

[15]. Deakin, L.; Arif, A.M.; Miller, J.S. Inorg. Chem. 1999, 38, 5072-5077.

[16]. Mukherjee, P.S.; Maji, T.K.; Mostafa, G.; Ribas, J.; Fallah, M.S.E.; Chaudhuri, N.R. Inorg. Chem. 2001, 40, 928-931.

[17]. Gatteschi, D.; Sessoli, R.; Cornia, A. Chem. Commun. 2000, 725-732.

[18]. Gatteschi, D.; Sessoli, R. Angew. Chem. 2003, 115, 278-309; Angew. Chem. Int. Ed. 2003, 42, $268-297$.

[19]. Sato, O.; Tao, J.; Zhang, Y.-Z. Angew. Chem. 2007, 119, 2200-2236; Angew. Chem. Int. Ed. 2007, 46, 21522187.

[20]. Felthouse, T.R.; Laskowski, E.J.; Hendrickson, D.N. Inorg. Chem. 1977, 16, 1077-1089.

[21]. a) Julve, M.; Verdaguer, M.; Gleizes, A.; Philoche-Levisalles, M.; O. Kahn, O. Inorg. Chem. 1984, 23, 38083818; b) Alvarez, S.; Julve, M.; Verdaguer, M. Inorg. Chem. 1990, 29, 4500-4507.

[22]. Verdaguer, M.; Gouteron, J.; Jeannin, S.; Jeannin, Z.; Kahn, O. Inorg. Chem. 1984, 23, 4291-4296.

[23]. a) Bakalbassis, E.G.; Tsipis, C.A.; Mrozinski, J. Inorg. Chem. 1985, 24, 4231-4233; b) Bakalbassis, E.G.; Mrozinski, J.; Tsipis, C.A. Inorg. Chem. 1986, 25, 3684-3690; c) Xanthopoulos, C.A.; Sigalas, M.P.; Katsoulos, G.A.; Tsipis, C.A.; Terzis, A.; Mentzafos, M.; Hountas, A. Inorg. Chem. 1993, 32, 5433-5436.

[24]. Chaudhuri, P.; Oder, K.; Wieghardt, K.; Gehring, S.; Haase, W.; Nuber, B.; Weiss, J. J. Am. Chem. Soc. 1988, 110, 3657-3658.

[25]. Coffman, R.E.; Buettner, G.R. J. Phys. Chem. 1979, 83, 2387-2392.

[26]. Burger, K.S.; Chaudhuri, P.; Wieghardt, K.; Nuber, B. Chem. Eur. J. 1995, 1, 583-589.

[27]. Erasmus, C.; Haase, W. Spectrochim. Acta, Ser. A 1994, 50,2189-2195.

[28]. Cano, J.; De Munno, G.; Sanz, J.L.; Ruiz, R.; Faus, J.; Lloret, F.; Julve, M.; Caneschi, A. J. Chem. Soc. Dalton Trans. 1997, 1915-1923.

[29]. Journaux, Y.; Glaser, T.; Steinfeld, G.; Lozan, V.; Kersting, B. Dalton Trans. 2006, 1738- 1748. 
[30]. Magnetism: Molecules to Materials (Eds.: Miller, J.S.; Drillon M.), Wiley-VCH, Weinheim, 2001.

[31]. Coronado, E.; Delhaes, P.; Gatteschi, D.; Miller, J.S.; Eds., Molecular Magnetism: From Molecular Assmblies to Devices, NATO ASI Series, Kluwer, Dordrecht, The Netherlands, 1995, vol. 321.

[32]. Watton, S.P.; Fuhrmann, P.; Pence, L.E.; Caneschi, A.; Cornia, A.; Abbati, G.L.; Lippard, S.J. Angew. Chem. 1997, 109, 2917-2919; Angew. Chem. Int. Ed. Engl. 1997, 36, 2774-2776.

[33]. Larionova, J.; Gross, M.; Pilkington, M.; Andres, H.; Stoeckli-Evans, H.; Güdel, H.U.; Decurtins, S. Angew. Chem. 2000, 112, 1667-1672; Angew. Chem. Int. Ed. 2000, 39, 1605-1609.

[34]. Dearden, A.L.; Parsons, S.; Winpenny, R.E.P. Angew. Chem. 2001, 113, 155-158; Angew. Chem. Int. Ed. 2001, 40, 151-154.

[35]. Demeshko, S.; Leibeling, G.; Dechert, S.; Meyer, F. Dalton Trans. 2006, 3458-3465.

[36]. Kersting, B.; Steinfeld, G.; Siebert, D. Chem. Eur. J. 2001, 7, 4253-4258.

[37]. a) Gressenbuch, M.; Kersting, B. Eur. J. Inorg. Chem. 2007, 90-102. b) Klingele, J.; Klingele, M.H.; Baars, O.; Lozan, V.; Buchholz, A.; Leibeling, G.; Plass, W.; Meyer, F.; Kersting, B. Eur. J. Inorg. Chem. 2007, 52775285.

[38]. Nakamoto, K. Infrared and Raman Spectra of Inorganic and Coordination Compounds, John Wiley \& Sons, New York, 1986.

[39]. Cotton, F.A.; Donahue, J.P.; Lin, C.; Murillo, C.A. Inorg. Chem. 2001, 40, 1234-1244.

[40]. Bakalbassis, E.G.; Bozopoulos, A.P.; Mrozinski, J.; Rentzeperis, P.J.; Tipsis, C.A. Inorg. Chem. 1988, 27, 529532.

[41]. Hong, C.S.; Yoon, J.H.; Lim, J.H.; Ko, H.H. Eur. J. Inorg. Chem. 2005, 4818-4821.

[42]. Shakhatreh, S.K.; Bakalbassis, E.G.; Bruedgam, I.; Hartl, H.; Mrozinski, J.; Tsipis, C.A. Inorg. Chem. 1991, 30, 2801-2806.

[43]. Ma, C.; Chen, C.; Liu, Q.; Chen, F.; Liao, D.; Li, L.; Sun, L. Eur. J. Inorg. Chem. 2004, 3316-3325.

[44]. Bourne, S.A.; Lu, J.J.; Mondal, A.; Moulton, B.; Zaworotko, M.J. Angew. Chem. 2001, 113, 2169-2171; Angew. Chem. Int. Ed. 2001, 40, 2111-2114.

[45]. Bayly, S., McCleverty, J.A., Ward, M.D., Gatteschi, D., Totti, F. Inorg. Chem. 2000, 39, 1288-1293.

[46]. Li, L., Liao, D., Jiang, Z., Yan, S. Inorg. Chem. 2002, 41, 421-424.

[47]. Deng, Z.L., Shi, J., Jiang, Z.H., Liao, D.Z., Yan, S.P., Wang, G.L., Wang, H.G., Wang, R.J. Polyhedron 1992, 11, 885-887.

[48]. Ferrocenes (Eds.: Togni, A.; Hayashi, T.), VCH, Weinheim, 1995.

[49]. a) Cotton, F.A.; Donahue, J.P.; Murillo, C.A. Inorg. Chem. 2001, 40, 2229 - 2233; b) Cotton, F.A.; Lin, C.; Murillo, C.A. Inorg. Chem. 2001, 40, 478-484.

[50]. Astruc, D. Electron Transfer and Radical Processes in Transition-Metal Chemistry, Wiley-VCH, Weinheim, 1995.

[51]. Hall, C.D.; Truong, T.-K.-U.; Tucker, J. H. R.; Steed, J.W. Chem. Commun. 1997, 2195- 2196.

[52]. a) DeBlass, A.M.; DeSantis, C.; Fabrizzi, L.; Liccheli, M.; Pallavicini, P.; Poggi, A. in Supramolecular Chemistry (Eds.: Balzani, V.; DeCola L.), Kluwer Academic Publishers, London, 1995, 87 -93; b) Steed, J.W.; Atwood, J.L. Supramolecular Chemistry, Wiley, Chichester, 2000, $224-230,574-639$.

[53]. Christie, S.D.; Subramanian, S.; Thomson, L.K.; Zaworotko, M.J. Chem. Commun. 1994, 2563 - 2564.

[54]. Metzler-Nolte, N.; Severin, K. in Concepts and Models in Bioinorganic Chemistry (Eds.: Kraatz, H.-B.; MetzlerNolte, N.), Wiley-VCH, Weinheim, 2006, $113-133$.

[55]. Matsue, T.; Evans, D.H.; Osa, T.; Kobayashi, N. J. Am. Chem. Soc. 1985, 107, 3411-3417.

[56]. a) Beer, P.D. Chem. Commun. 1996, 689 -696; b) Beer, P.D.; Keefe, A.D.; Slawin, A. M.Z.; Williams, D.J. J. Chem. Soc. Dalton Trans. 1990, 3675-3682; c) Beer, P.D. Acc. Chem. Res. 1998, 31, 71- 80.

[57]. Medina, J.C.; Goodnow, T.T.; Rojas, M.T.; Atwood, J.L.; Lynn, B.C.; Kaifer, A.E.; Gokel, G.W. J. Am. Chem. Soc. 1992, 114, $10583-10595$.

[58]. Atwood, J.L.; Holman, K.T.; Steed, J.W. Chem. Commun. 1996, 1401 - 1408.

[59]. M'hamed Chahma, Lee, J.S.; Kraatz, H.-B. J. Organomet. Chem. 2002, 648, 81-86.

[60]. a) Harriman, A.; Ziessel, R. Chem. Commun. 1996, 1707 -1716; b) Buda, M.; Moutet, J.-C.; Saint-Arman, E.; DeCian, A.; Fischer, J.; Ziessel, R. Inorg. Chem. 1998, 37, 4146-4148; c) Ion, A., Moutet, J.-C.; Saint-Aman, E.; Royal, G.; Tingry, S.; Pecaut, J.; Menage, S.; Ziessel, R. Inorg. Chem. 2001, 40, 3632 -3636; d) Moutet, J.-C.; Saint-Aman, E.; Royal, G.; Tingry, S.; Ziessel, R. Eur. J. Inorg. Chem. 2002, 692-698.

[61]. Butler, I.R.; Kalaji, M.; Nehrlich, L.; Hursthouse, M.; Karaulov, A.I.; Abdul Malik, K.M. J. Chem. Soc. Chem. Commun. 1995, $459-460$.

[62]. Houlton, A.; Jasim, N.; Roberts, R.M.G.; Silver, J.; D. Cunningham, D.; McArdle, P.; Higgins, T. J. Chem. Soc. Dalton Trans. 1992, 2235- 2241. 
[63]. Beer, P.D.; Nation, J.E.; McWhinnie, S.L.W.; Harman, M.E.; Hursthouse, M.B.; Ogden, M.I.; White, A.H. J. Chem. Soc. Dalton Trans. 1991, 2485- 2492.

[64]. a) Cotton, F.A.; Lin, C.; Murillo, C.A. Inorg. Chem. 2001, 40, 472 - 477; b) Cotton, F.A.; Donahue, J.P.; Lin, C.; Murillo, C.A. Inorg. Chem. 2001, 40, $1234-1244$.

[65]. Kersting, B.; Steinfeld, G. Chem. Commun. 2001, 1376-1377.

[66]. Klingele, M.H.; Steinfeld, G.; Kersting, B. Z. Naturforsch. 2001, 56b, $901-907$.

[67]. Hausmann, J.; Klingele, M.H.; Lozan, V.; Steinfeld, G.; Siebert, D.; Journaux, Y.; Girerd, J.J.; Kersting, B. Chem. Eur. J. 2004, 10, 1716 -1728.

[68]. Journaux, Y.; Lozan, V.; Hausmann, J.; Kersting, B. Chem. Commun. 2006, 83-84.

[69]. Kersting, B. Angew. Chem. 2001, 113, 4110 - 4112; Angew. Chem. Int. Ed. 2001, 40, 3988 - 3990.

[70]. Kersting, B.; Steinfeld, G. Inorg. Chem. 2002, 41, 1140-1150.

[71]. Steinfeld, G.; Lozan, V.; Kersting, B. Angew. Chem. 2003, 115, 2363 - 2365; Angew. Chem. Int. Ed. 2003, 42, $2261-2263$.

[72]. Churchill, M.R.; Li, Y.-J.; Nalewajek, D.; Schaber, P.M.; Dorfman, J. Inorg. Chem. 1985, 24, $2684-2687$.

[73]. Costa, R.; Lopez, C.; Molins, E.; Espinosa, E. Inorg. Chem. 1998, 37, 5686 - 5689.

[74]. Klingert, B.; Rihs, G. Organometallics 1990, 9, 1135- 1141.

[75]. Lozan, V.; Buchholz, A.; Plass, W.; Kersting, B. Chem.Eur. J., 2007,13, 7305-7316.

[76]. Gressenbuch, M.; Lozan, V.; Steinfeld, G.; Kersting, B. Eur. J. Inorg. Chem. 2005, 2223-2234;

[77]. Lang, H.; K3hler, K.; Zsolnai, L. Chem. Ber. 1995, 128, 519 -523.

[78]. Lozan, V.; Kersting, B. Eur. J. Inorg. Chem. 2005, 504 -512.

[79]. Tao, J.; Xiao, W. J. Organomet. Chem. 1996, 526, 21- 24.

[80]. Sabbatini, M.; Franco, M.A.; Psaro, R. Inorg. Chim. Acta 1980, 42, $267-270$.

[81]. Wang, X.-B.; Dai, B.; Woo, H.-K.; Wang, L.-S. Angew. Chem. 2005, 117, 6176 -6178; Angew. Chem. Int. Ed. $2005,44,6022-6024$.

[82]. Robin, M.B.; Day, P. Adv. Inorg. Chem. Radiochem. 1967, 10, 247-422.

[83]. Takusagawa, F.; Koetzle, T.F. Acta Crystallogr. Sect. B 1979, 35, 1074 - 1081.

[84]. Cooke, M.W.; Cameron, T.S.; Robertson, K.N.; Swarts, J.C.; Aquino, M.A.S. Organometallics 2002, 21, 5962 -5971 .

[85]. Aquino, M.A.S. Coord. Chem. Rev. 1998, 170, 141 -202.

[86]. Lopez, C.; Costa, R.; Illas, F.; Molins, E.; Espinosa, E. Inorg. Chem. 2000, 39, 4560-4565.

[87]. Takusagawa, F.; Koetzle, T.F. Acta Crystallogr. Sect. B 1979, 35, 2888 - 2896.

[88]. Palenik, G.J. Inorg. Chem. 1969, 8, $2744-2749$.

[89]. Tyler, L.A.; Noveron, J.C.; Olmstead, M.M.; Mascharak, P.K. Inorg. Chem. 2000, 39, 357- 362.

[90]. Higgs, T.C.; Ji, D.; Czernuszewicz, R.S.; Matzanke, B.F.; V. Schünemann, V.; Trautwein, A.X.; Helliwell, M.; Ramirez, W.; Carrano, C.J. Inorg. Chem. 1998, 37, 2383 -2392.

[91]. a) Cotton, F.A.; Donahue, J.P.; Murillo, C.A.; Perez, L.M. J. Am. Chem. Soc. 2003, 125, 5486 -5492; b) Chisholm, M.H.; Pate, B.D.; Wilson, P.J.; Zalewski, J.M. Chem. Commun. 2002, $1084-1085$.

[92]. De Santis, G.; Fabrizzi, L.; Licchelli, M.; Pallavicini, P. Inorg. Chim. Acta. 1994, 225, 239 - 244.

[93]. Beer, P.D. Chem. Soc. Rev. 1989, 18, $409-450$.

[94]. Katz, H.E.; Lovinger, A.J.; Kloc, C.; Slegrist, T.; W. Li, W.; Lin, Y.-Y.; Dodabalapur, A. Nature, 2000, 404, 478-481.

[95]. Bhosale, S.V.; Jani, C.H.; Langford, S.J. Chem. Soc. Rev., 2008, 37, 331-342.

[96]. Andric, G.; Boas, J.F.; Bond, A.M.; Fallon, G.D.; Ghiggino, K.P.; Hogan, C.F.; Hutchison, J.A.; Lee, M. A.-P.; Langford, S.J.; Pilbrow, J.R.; Troup, G.J.; Woodward, C.P. Aust. J. Chem., 2004, 57, 1011-1019.

[97]. Bauscher, M.; Mantele, W. J. Phys. Chem, 1992, 96, 11101-11108.

[98]. Langford, S.J.; Latter, M.J.; Woodward, C.P. Photochem. Photobiol., 2006, 82, 1530-1540.

[99]. Fallon, G.D.; Lee, M.A-P.; Langford, S.J. Acta Crystallogr., Sect.E, 2004, 60, o542-o543.

[100]. Lee, K.A.; Lozan, V.; Langford, S.J.; Kersting, B. Dalton Trans., 2009, 7481-7485.

[101]. Liu, S.-G.; Sui, G.; Cormier, R.A.; Leblancand, R.M.; Gregg, B.A. J. Phys. Chem. B, 2002, 106, $1307-1315$.

[102]. Lee, H.N.; Xu, Z.; Kim, S.K.; Swamy, K.M.K.; Kim, Y.; Kimand, S.-J.; Yoon, J. J. Am. Chem. Soc., 2007, 129, 3828-3829.

[103]. P. Ganesan, P.; Van Lagen, B.; Marcelis, A.T.; Sudhlter, E.J.R.; Zuilhof, H. Org. Lett., 2007, 9, $2297-2300$.

[104]. Meyer, E.A.; Castellano, R.K.; Diederich, F. Angew. Chem., 2003, 115, 1244-1287; Angew. Chem., Int. Ed., 2003, 42, 1210-1250. 